\title{
Opsonization by non-neutralizing antibodies can confer protection to SARS-CoV-2 despite Spike-dependent modulation of phagocytosis
}

\author{
Wael Bahnan ${ }^{\mathrm{a} \bowtie}$, Sebastian Wrighton ${ }^{\mathrm{a}}$, Martin Sundwall ${ }^{\mathrm{a}}$, Anna Bläckberg ${ }^{\mathrm{a}, \mathrm{b}}$, Urban Höglund ${ }^{\mathrm{c}}$, Olivia Larsson ${ }^{\mathrm{c}}$, Hamed \\ Khakzad $^{\mathrm{d}, \mathrm{e}}$, Magdalena Godzwon ${ }^{\mathrm{f}}$, Maria Walle ${ }^{\mathrm{f}}$, Elizabeth Elder ${ }^{\mathrm{g}}$, Lotta Happonen ${ }^{\mathrm{a}}$, Oscar Andréa ${ }^{\mathrm{a}}$, Johannes Kumra \\ Ahnlide $^{\mathrm{a}}$, Thomas Hellmark ${ }^{\mathrm{h}}$, Vidar Wendel-Hansen ${ }^{\mathrm{i}}$, Robert PA Wallin ${ }^{\mathrm{j}}$, Johan Malmström ${ }^{\mathrm{a}}$, Lars Malmström ${ }^{\mathrm{a}, \mathrm{k}}$, Mats Ohlin $^{\mathrm{f}}$, \\ Magnus Rasmussen ${ }^{\mathrm{a}, \mathrm{b}}$, and Pontus Nordenfelt ${ }^{\mathrm{a} \triangle}$ \\ aLund University, Faculty of Medicine, Department of Clinical Sciences Lund, Infection Medicine, SE-22184 Lund, Sweden. \\ ${ }^{\mathrm{b}}$ Infectious Disease Clinic, SUS, Lund, Sweden \\ ${ }^{\mathrm{c}}$ Adlego Biomedical AB, Uppsala, Sweden \\ ${ }^{\mathrm{d}}$ Equipe Signalisation Calcique et Infections Microbiennes, Ecole Normale Superieure Paris-Saclay, 91190 Gif-sur-Yvette, France \\ ' Institut National de la Sante et de la Recherche Medicale (INSERM) U1282, 91190 Gif-sur-Yvette, France \\ f Lund University, Department of Immunotechnology, Lund, Sweden \\ ${ }^{g}$ Public Health Agency of Sweden, 17182 Solna, Sweden \\ hLund University, Skane University Hospital, Department of Clinical Sciences Lund, Nephrology, Lund, Sweden. \\ i Tanea Medical Ab, Uppsala, Sweden \\ jSciEd Solutions, Stockholm, Sweden \\ ${ }^{\mathrm{k}}$ Institute for Computational Science, University of Zurich, Winterthurerstrasse 190, CH-8057 Zurich, Switzerland.
}

\begin{abstract}
Spike-specific antibodies are central to effective COVID19 immunity. Research efforts have focused on antibodies that neutralize the ACE2-Spike interaction but not on non-neutralizing antibodies. Antibody-dependent phagocytosis is an immune mechanism enhanced by opsonization, where typically, more bound antibodies trigger a stronger phagocyte response. Here, we show that Spike-specific antibodies, dependent on concentration, can either enhance or reduce Spike-bead phagocytosis by monocytes independently of the antibody neutralization potential. Surprisingly, we find that both convalescent patient plasma and patient-derived monoclonal antibodies lead to maximum opsonization already at low levels of bound antibodies and is reduced as antibody binding to Spike protein increases. Moreover, we show that this Spike-dependent modulation of opsonization seems to affect the outcome in an experimental SARS-CoV-2 infection model. These results suggest that the levels of antiSpike antibodies could influence monocyte-mediated immune functions and propose that non-neutralizing antibodies could confer protection to SARS-CoV-2 infection by mediating phagocytosis.
\end{abstract}

SARS-CoV-2 | Spike protein | antibody binding | antibody function | phagocytosis | in vivo model

Correspondence: pontus.nordenfelt@med.lu.se; wael.bahnan@med.lu.se

\section{Introduction}

COVID19, caused by the SARS-CoV-2 virus, has since the end of 2019 resulted in millions of deaths and serious societal health effects. Treatment of patients with convalescence plasma or monoclonal antibodies was attempted early on during the pandemic, inspired by previous partial successes with Respiratory Syncytial Virus (1) and Ebola (2). Two monoclonal antibody cocktails targeting the SARS-CoV-2 Spike protein (casirivimab and imdevimab) (3) and (bamlanivimab and etesevimab) (4, 5) were given emergency use authorization by the FDA after positive phase III clinical trial data. Trials showed that antibody cocktails reduced symptoms, hospitalization, and mortality associated with COVID19 for early-stage infections. However, studies regarding their use for treating severe COVID19 showed no clinical benefit (6).

The therapeutic antibodies described previously neutralize the interaction between the Spike protein and the ACE2 receptor, thereby hindering viral entry into host cells. Considerable efforts have been made to generate neutralizing anti-Spike antibodies (7, 8, 9, 10). Neutralizing antibodies, however, constitute only a fraction of the antibody repertoire generated by $\mathrm{B}$ cells against the Spike protein during COVID19 infection (11). The opsonic capability has not been a focal point in the characterization of neutralizing antibodies. Non-neutralizing antibodies, comprising the majority of the humoral immune response to a pathogen, have other immunological functions such as complement-dependent immune activation and viral phagocytosis (reviewed by Forthal (12)). Phagocytosis plays a substantial role in the anti-viral immune response (13). Through virion or cellular phagocytosis, phagocytic cells help reduce the viral load by eliminating infection sources. In this context, we were interested in whether or not Spike antibodies might mediate phagocytosis as has been previously seen with influenza (13, 14, 15).

However, in other viral infections (such as Dengue, SARSCoV-2, Respiratory Syncytial Virus, and others), insufficient levels of neutralizing antibodies allow non-neutralizing antibodies to mediate the entry of virions into host immune cells (16). This infection of immune cells via Fc $\gamma \mathrm{R}$ leads to Antibody-Dependent-Enhancement (ADE), exacerbating the infection and worsening patient outcomes (17). So far, studies on COVID19 vaccines and monoclonal antibodies utilized in COVID19 therapy have seen no evidence of 
ADE (16, 17, 18, 19, 20, 21). This clinical absence of ADE remains true even when some studies report that patient sera with high titers of neutralizing antibodies could induce Spike-bead phagocytosis or $\mathrm{Fc} \gamma \mathrm{R}$-activation (ADCP) (22, 23, 24).

Our work shows evidence that convalescent patient plasma and monoclonal anti-Spike antibodies induce phagocytosis but with diminishing returns when the antibody concentrations become high. We also demonstrate that the activation and inhibition of phagocytosis are independent of neutralization potential. Finally, we present data from an experimental animal infection model showing that non-neutralizing antibodies can protect animals from SARS-CoV-2 infection. The results in this study shed light on the importance of nonneutralizing antibodies in mediating phagocytosis and how their presence translates into protection after experimental infection.

\section{Results}

Convalescent patient plasma reduces Spike-monocyte interaction. Blood plasma was obtained from 20 COVID19 convalescent patients (Supp. Table 1). We used biotinylated Spike protein conjugated to streptavidin fluorescent microspheres ( $1 \mu \mathrm{m}$ beads) as a model for Spike-monocyte interactions. The beads were used as bait for THP-1 monocytes. To opsonize the beads, we incubated them with the patient plasma at different dilution levels. We chose the $0.01-1 \%$ concentrations to mimic IgG levels in the mucosal niche or tissues, which would be the first place of encounter with the SARS-CoV-2 virus. The highest level of association between plasma-opsonized Spike-beads and cells was at the intermediate plasma dilution $(0.1 \%)$, while the higher and lower concentrations of plasma ( 1 and $0.01 \%$, respectively) showed reduced association (Fig. 1a). In fact, the only consistent effect we saw across our patient plasma samples was a reduction in Spike-particle association with THP- 1 cells at the highest plasma concentration. This phenomenon was seen in 18 out of 20 patient samples. Two patient samples (patients 8 and 18) showed no or low opsonic ability. The reduction in Spike-THP-1 cell association under high plasma concentrations was independent of patient sex, age, or disease severity (Supp. Table 1).

As our results were unexpected, we checked whether the reduction in particle-to-cell association seen at higher plasma concentrations (1\%) was due to a loss of Spike or antibody binding. For that purpose, we methanol-fixed the samples from the experiment shown previously (Fig. 1a). The samples were then stained with a fluorescently conjugated (FITC) secondary antibody (Fab anti-human Fab), which would react with the plasma anti-Spike antibodies which had bound to Spike on the beads. Unsurprisingly, increased plasma concentrations led to increased binding of Spike-specific antibodies to the Spike-beads (Fig. 1b). In contrast, patients 8 and 18 showed no or very low binding of antibodies to Spike-beads, correlating with overall reduced opsonization (Fig. 1a). Our results show that when assayed at higher concentrations, patient plasma is not permissive to THP-1 cell-Spike interactions, despite having antibodies that readily bind Spike protein.

Generation of Spike-reactive human monoclonal
antibodies. Considering our previous data showing that high concentrations of COVID19 convalescent plasma reduced Spike-THP-1 cell interactions compared to low concentrations, we decided to identify the role monoclonal antibodies play in Spike-THP-1 cell interactions. We isolated Spike-reactive B cells from convalescent COVID19 patients and performed single-cell sequencing (Fig. 2a). We chose 96 antibodies for production that were equidistantly spaced on the genetic clustering tree (Supp. Fig. 1a). The antibodies were expressed in HEK293 cells. ELISA-based screening of the antibody-containing supernatants allowed us to identify ten Spike-reactive antibodies (Fig. 2b, Supp. Fig. 1b-c), which belonged to different IgG germlines (Supp. Fig. 1d). The Spike-reactive antibodies were then assayed for reactivity against Spike-beads using flow cytometry, where we observed that nine antibodies were reactive to the Spike-beads (Fig. 2c). Ab11, 57, 59, 66, 77, 81, 94, and 95 showed clear reactivity ( $>40 \%$ positive beads) when assayed with Spike-beads at a concentration of $1 \mu \mathrm{g} / \mathrm{ml}$. Ab59 demonstrated strongest binding, as could be seen through the relative increase in bead staining. Xolair (used at $10 \mu \mathrm{g} / \mathrm{ml}$ ) and normal (pre-COVID19) plasma served as negative controls, whereas COVID19 plasma from a convalescent patient was our positive control.

Epitope mapping and structural mass spectrometry identify antibody binding sites. To identify antibody binding sites, we first used ELISA to study Spike domain interactions with RBD, RBD with L452R and T478K mutations (delta), and NTD from Spike (Fig. 3a). We could detect binding to seven antibodies, with high integrated signal (0.2-30 nM titration curves) for Ab59, Ab66, Ab81, and Ab94. Ab66 showed stronger interaction with delta RBD, and Ab 81 showed a lower signal. Ab94 only bound the NTD of Spike. We also performed relative antibody epitope mapping using the single-chain antibody fragments $(\mathrm{scFv})$ isolated from an extensive combinatorial library. $\mathrm{scFv}$ mapping revealed that the Ab59 epitope overlaps with those of two scFv (A03_D03 and E01_C09, Fig. 3b) that interfere in the binding of Spike to ACE2.

Next, we used TX-MS (25) to determine the binding interface between the SARS-CoV-2 specific antibodies and the RBD domain of the Spike protein. In short, we cross-linked the ten antibodies separately to the RBD domain, followed by mass spectrometry analysis and structural modeling (26). This resulted in the identification of 11 confident inter-protein XLs between the RBD domain and five of the antibodies (Ab11, Ab57, Ab66, Ab77, and Ab94) in addition 
bioRxiv preprint doi: https://doi.org/10.1101/2021.10.14.464464; this version posted October 15,2021 . The copyright holder for this preprint (which was not certified by peer review) is the author/funder, who has granted bioRxiv a license to display the preprint in perpetuity. It is made available under aCC-BY-NC-ND 4.0 International license.

Figure 1

a Phagocytosis

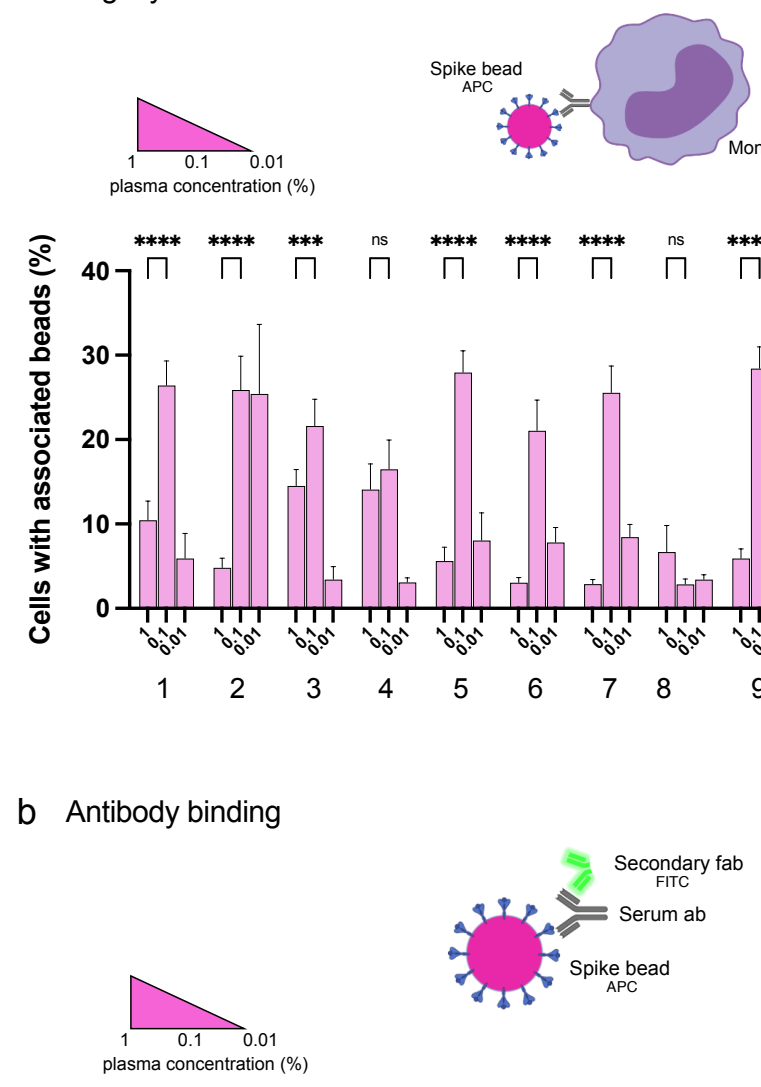

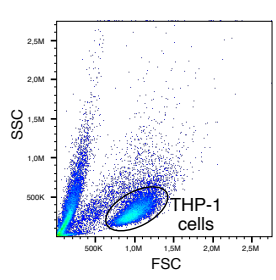

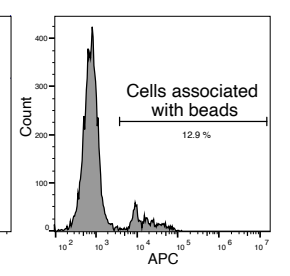

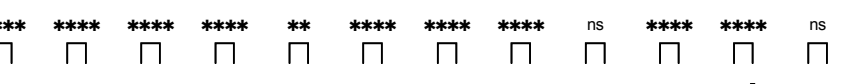
i

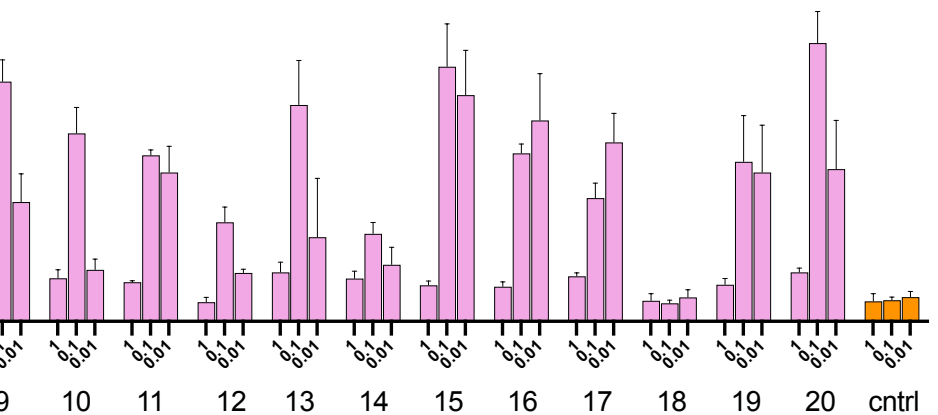

Patient

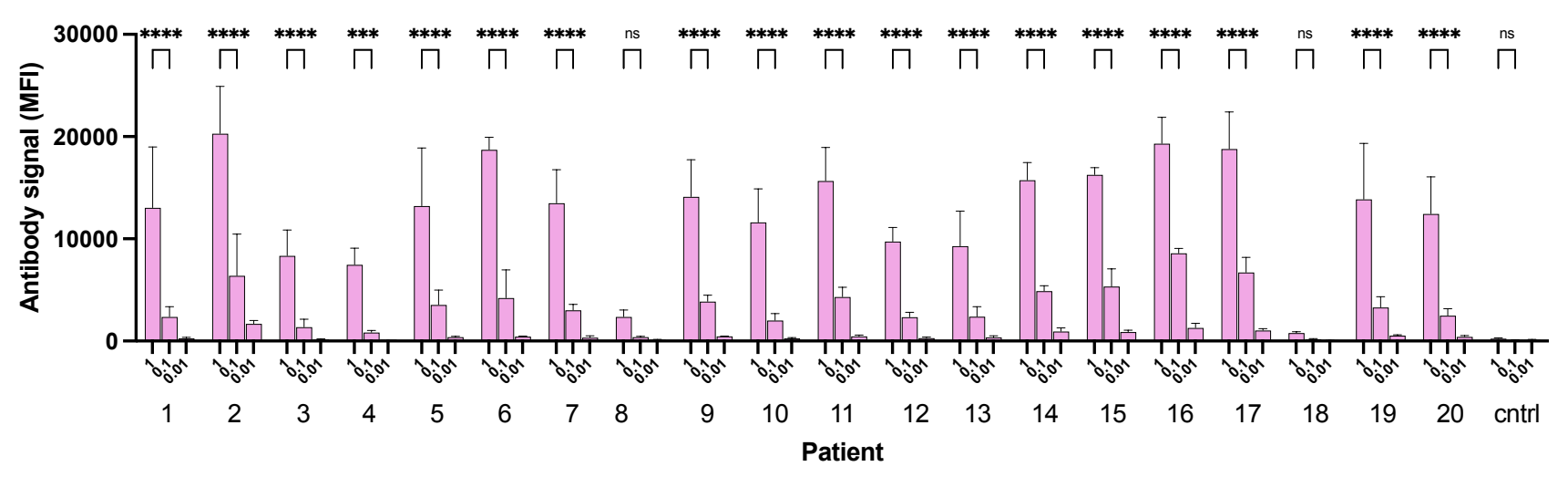

Fig. 1. Convalescent patient plasma reduces Spike-monocyte interaction. a Biotinylated Spike protein was conjugated to fluorescent (APC) streptavidin microspheres and was opsonized with three convalescent patient plasma concentrations ( $1 \%, 0.1 \%$, and $0.01 \%)$. The beads were then mixed with THP-1 cells at a ratio of $2: 1$, and the association was measured using flow cytometry. Cells that had signal in the APC channel were considered positive. The gating strategy is shown in the top right. $\mathbf{b}$ The same samples of THP-1 cells and beads from (a) were fixed with methanol and stained with a fluorescent (FITC) Fab anti-human Fab secondary antibody. The samples were analyzed for human antibody (opsonin) binding to the Spike-beads using flow cytometry. The gating strategy is shown in the top right. The data presented are from three independent experiments. Error bars represent the SD. Statistical significance was assessed using two-way ANOVA with Dunnett's multiple comparison correction. * denotes

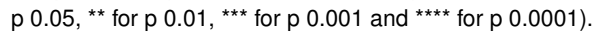

to 30 intra RBD XLs (Fig. 3c, Supp Fig 3). The results show that the five antibodies can bind to the Spike protein, but they do not appear to compete with the binding site of human ACE2 directly. The interaction between Ab66 and Spike protein show binding to the open-state but not the closed-state (Fig. 3d). Further, the structural model indicates no competition between Ab66 and human ACE2, which is in accordance with previously published work, as only the open-state is responsible for binding human ACE225. In contrast, Ab94 appears to preferably bind the closed state (Fig. 3e). The combined data from our epitope analysis approaches indicate that Ab11, 57, 59, 66, 77, 81 bind Spike RBD, that Ab94 could interact with both RBD and NTD, and that Ab59 could be a neutralizing antibody, whereas the others are likely non-neutralizing. 
bioRxiv preprint doi: https://doi.org/10.1101/2021.10.14.464464; this version posted October 15, 2021. The copyright holder for this preprint (which was not certified by peer review) is the author/funder, who has granted bioRxiv a license to display the preprint in perpetuity. It is made available under aCC-BY-NC-ND 4.0 International license.

Figure 2

a Monoclonal generation from patient B cells
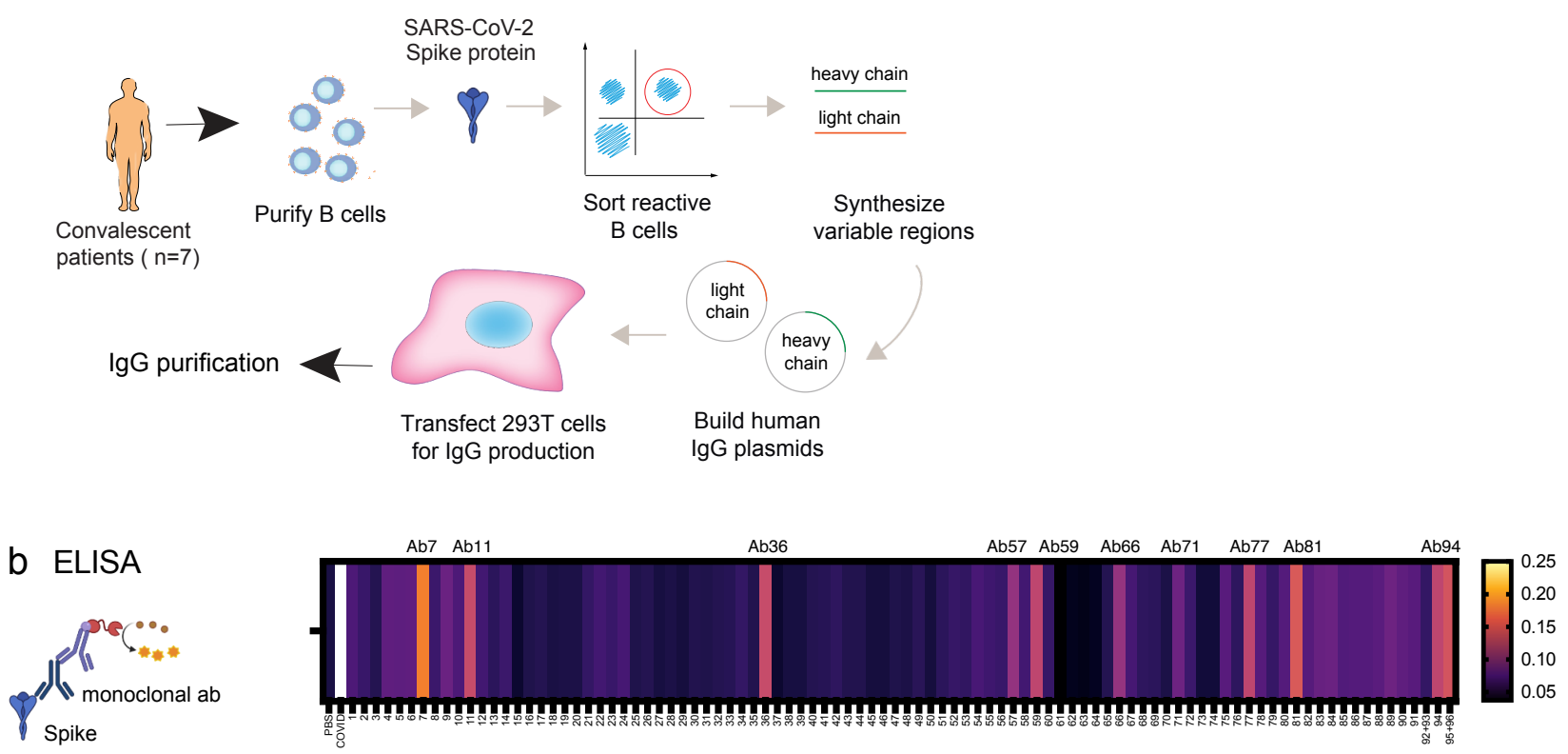

\section{Antibody binding}
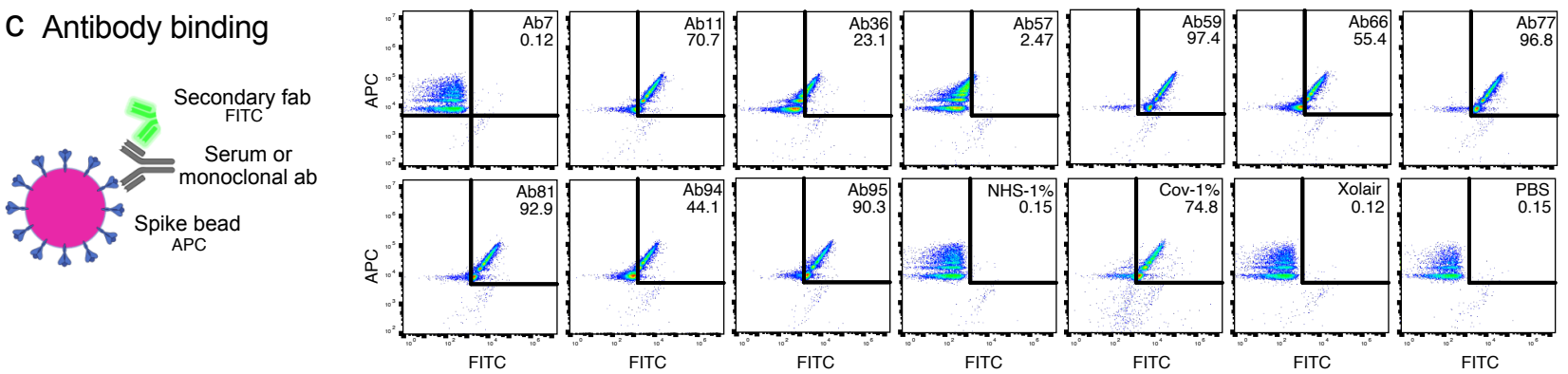

Fig. 2. Generation of Spike-reactive human monoclonal antibodies. a Human monoclonal antibodies were generated from convalescent donor $B$ cells through single-cell sequencing technology. 96 antibodies derived from Spike-reactive human B cells were produced in HEK293F cells. b Cell culture supernatants containing the antibodies were assayed by ELISA for reactivity against immobilized Spike protein. Serum from a COVID19 patient was used as a positive control. The data represent three replicate ELISAs where reproducibly reactive antibodies are indicated with their names above the heatmap. c Antibodies which were Spike-reactive in (b) were assayed for reactivity to Spike immobilized on beads. Fluorescent (APC) Streptavidin beads coated with biotinylated Spike protein were incubated with HEK293F-produced antibodies at a concentration of $1 \mu \mathrm{g} / \mathrm{ml}$. The beads were then stained with a fluorescent (FITC) secondary anti-Fab antibody. The beads were analyzed by flow cytometry. Antibodies that shifted the beads into the FITC-positive gate were deemed reactive.

\section{Neutralization assays identify one monoclonal which blocks the ACE2-Spike protein interaction. Typi-} cally, the most important biological function attributed to antibodies in the context of a viral infection is neutralization. We assayed our Spike-reactive antibodies for Spike-neutralization using three different approaches: Spike RBD-ACE2 protein binding (Fig. 4a), Spike particle-ACE2 cell interaction (Fig. 4b), and SARS-CoV-2 pseudovirus infection neutralization (Fig. 4c). The SPR-based Spike RBD-ACE2 binding data showed that Ab36 and Ab94 did not appear to interfere with RBD-ACE2 binding and that Ab57 reduced binding slightly. Ab59 completely blocked RBD-ACE binding, whereas Ab66, Ab77, and Ab81 seemed to bind well without interfering with the interaction. Next, we utilized ACE2-expressing HEK293 cells as a surrogate for lung epithelial cells. We measured the ability of Spike-beads to bind HEK293-ACE2+ cells after being opsonized with antibody supernatants. We assayed all 96 of our antibody-containing supernatants for Spike-particle neutralization. Only Ab59 showed a robust and reproducible reduction in Spike-particle binding to HEK293-ACE2+ cells compared to COVID19 patient plasma (Fig. 4b). As expected, pre-COVID19 plasma showed no inhibition of Spike-ACE2 interactions. Representative images of our experiments which were used for analysis, are shown in Supplementary Fig 2. We utilized a pseudovirus binding assay to verify the ability of our antibodies to neutralize SARS-CoV-2. Consistent with our previous experiments with RBD and Spike-beads (Fig 4a-b), we saw that Ab59 was the best $\left(\mathrm{EC}_{50}: 19 \mathrm{ng} / \mathrm{ml}\right)$ among our antibodies in neutralizing SARS-CoV-2 pseudovirus infection (Fig. 4c). Taken together, our results indicate that of our 96 antibodies, 

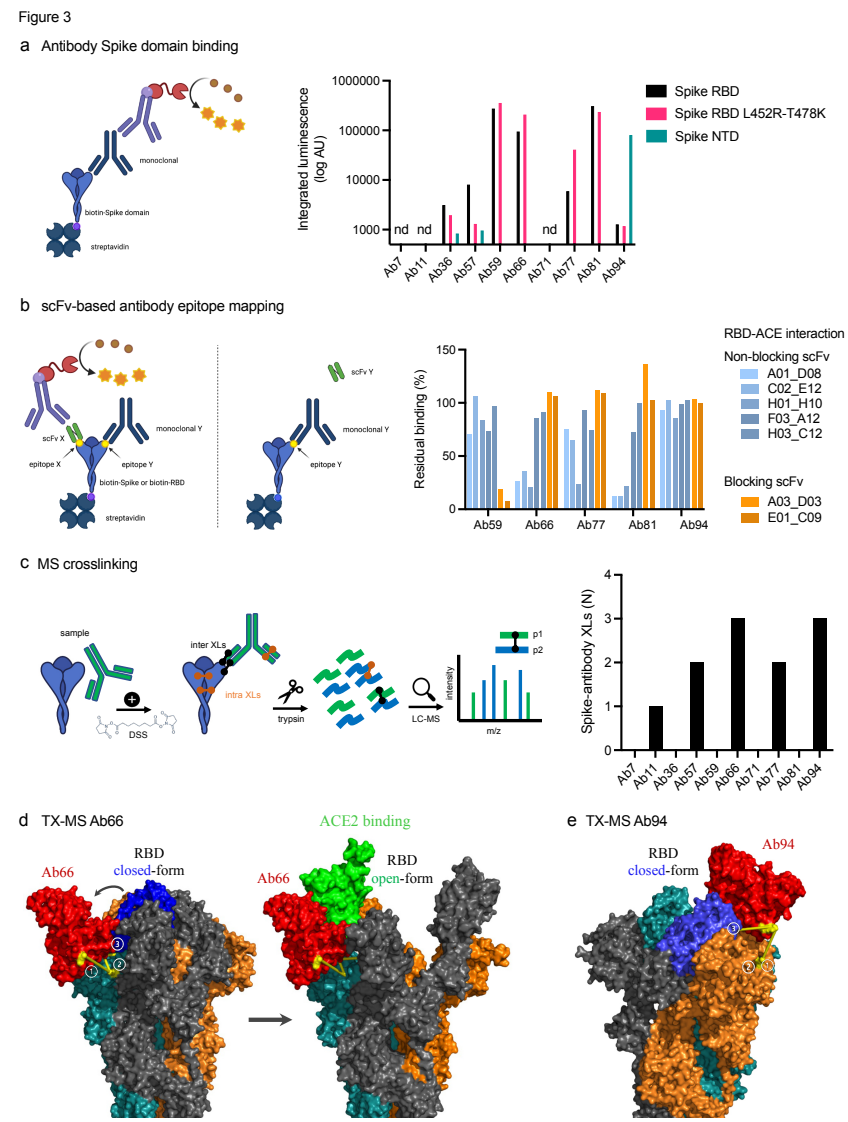

Fig. 3. Epitope mapping and structural mass spectrometry identify antibody binding sites. a Antibody binding to Spike domains was analyzed using ELISA as shown with HRP signal as readout. Antibodies were titrated at 0.2-30 nM, and the integrated signal was calculated. The relative binding to each Spike domain is shown. $\mathrm{nd}=$ not determined. b Epitope mapping was performed using scFvs targeting RBD epitopes as shown. Antibody blocking of scFv binding was measured using anti-FLAG HRP signal. Representative of two independent experiments. c Spike protein was mixed with anti-spike antibodies and the complex was crosslinked with DSS, allowing for inter and intra cross-links. After trypsinization, mass spectrometric analysis was performed. The table to the right displays the number of inter-protein cross-links detected between Spike and its corresponding antibody. d-e The binding sites for Ab66 and Ab94 were determined by TX-MS using the cross-links from c, and the data was modelled using Rosetta. Models for Ab66 (d) binding the Spike protein in both its open and closed conformations as well Ab94 (e) are shown.

only Ab59 is a potent neutralizer of the Spike-ACE2 interaction.

\section{High levels of human monoclonal antibodies reduce} Spike-monocyte interaction. Antibodies are the primary mediators of $\mathrm{Fc} \gamma \mathrm{R}$-dependent cellular interactions. Given our previous data that high concentrations of convalescent patient plasma can reduce Spike-bead association with THP1 monocytes (Fig 1.), we tested whether this reduction was antibody-driven. We chose antibody concentrations that were in a similar range $(100-0.01 \mu \mathrm{g} / \mathrm{ml})$ than what is expected at the plasma concentrations used $(1 \%-0.1 \%)$ (Fig. 1) and included a higher plasma concentration for comparison $(10 \%)$. Interestingly, as with patient blood plasma, serially diluted Spike-specific monoclonal antibodies showed the same inhibition trend of bead-to-cell association at the higher
Figure 4
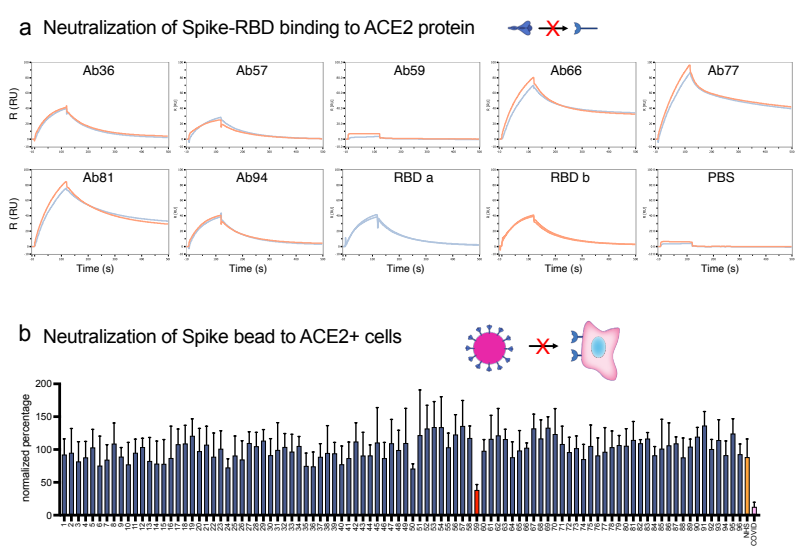

C Neutralization of pseudovirus infection to ACE2+ cells
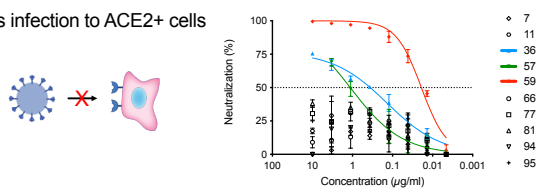

Fig. 4. Neutralization assays identify one monoclonal as blocking the ACE2Spike protein interaction. a SPR analysis of the binding of monoclonal antibodies to the RBD domain of the Spike protein. PBS served as a negative control, and the intact RBD was our positive control for ACE2 binding. b The 96 antibodies which we produced were assayed for neutralization potential in a Spike-bead-based neutralization assay. Spike-beads (such as the ones used in (b)) were opsonized with the antibodies in 96 well plates. The beads were then centrifuged, reconstituted in fresh media, and added to HEK293-ACE2 cells at a ratio of 20 beads per cell and imaged with automated microscopy. The data is from 4 pooled experiments and is presented as bead association normalized percentage. Error bars indicate the SEM for the replicate experiments. c The 10 Spike-ELISA reactive antibodies were assayed for pseudovirus neutralization. A firefly luciferase encoding pseudotype lentivirus was used to infect HEK239-ACE2 cells. Antibody serial dilutions were used to block the viral entry into the HEK293-ACE2 cells. Nonlinear regression lines were fitted for the three antibodies that showed a higher than $50 \%$ reduction of infectivity. Those antibodies were highlighted in green (Ab57), blue (Ab36), and red (Ab59).

concentrations (Fig. 5a). This association was confirmed to reflect the internalization of particles (i.e., phagocytosis) by using a pH-dependent fluorescent dye (Supp. Fig. 4). Also, as with plasma, this inhibition was correlated with increased antibody binding to Spike (Fig. 5b). It is important to note here that among the antibodies, Ab94 seemed to have almost half the binding efficiency of Ab59, an attribute that will be central for other experiments. The neutralizing antibody, Ab59, showed the same trend as the other non-neutralizing antibodies. We have thus identified that Spike-specific monoclonal antibodies isolated from COVID19 patients modulate the Spike-THP-1 cell interactions in a dose-dependent manner. This phenomenon is independent of the SpikeACE2 neutralization capability of the monoclonal antibodies.

Non-neutralizing antibodies can protect against SARS-CoV-2 infection. We have shown that among our antibodies, Ab59 is neutralizing while the other monoclonals are not. We have also demonstrated that our Spike-bead reactive antibodies are efficient at mediating Spike-mediated phagocytosis but reach a threshold after which there is a reduction in interaction efficacy. To test the antibodies' function in a physiologically relevant context, we assessed 
bioRxiv preprint doi: https://doi.org/10.1101/2021.10.14.464464; this version posted October 15, 2021. The copyright holder for this preprint (which was not certified by peer review) is the author/funder, who has granted bioRxiv a license to display the preprint in perpetuity. It is made available under aCC-BY-NC-ND 4.0 International license.

Figure 5

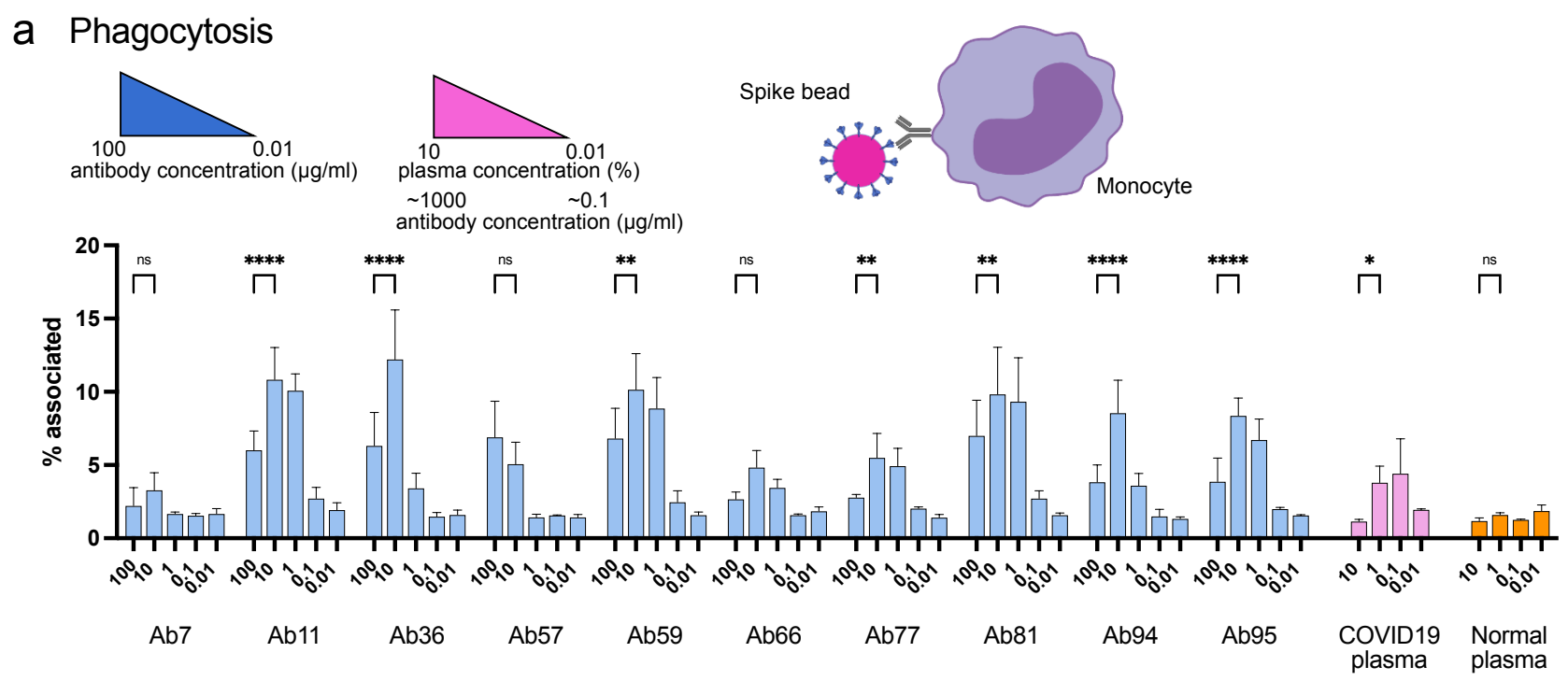

\section{b Antibody binding}
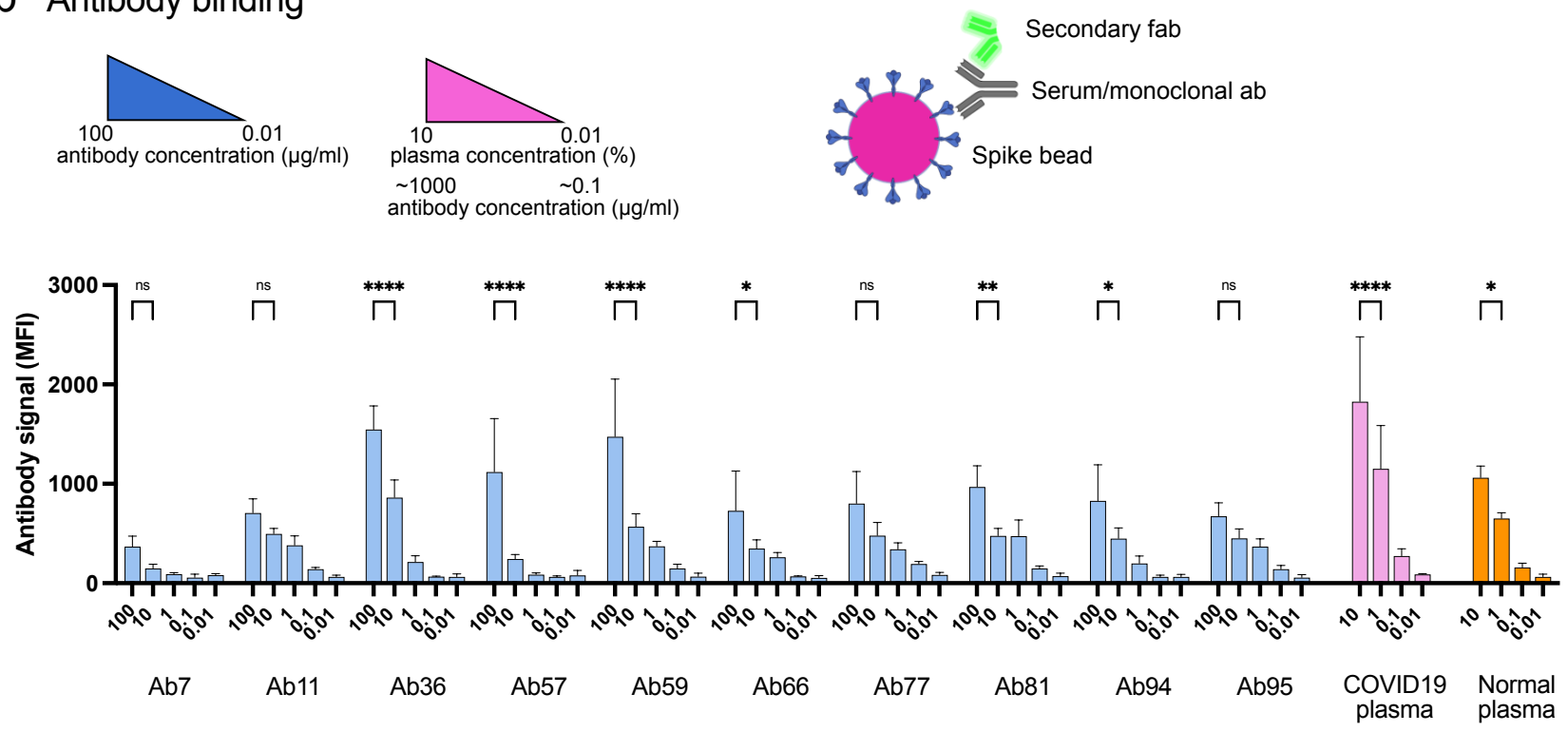

Fig. 5. High levels of human monoclonal antibodies reduce Spike-monocyte interaction. a Spike-reactive monoclonal antibodies at concentrations of $100,10,1,0.1$, and $0.01 \mu \mathrm{g} / \mathrm{ml}$ were used to opsonize Spike-beads. Plasma was used at serial dilutions of $10 \%$. The beads were then incubated with THP-1 cells at a ratio of 2 beads/cell. The cells were then analyzed by flow cytometry for association with the fluorescent Spike-beads. The data show the \% of bead-associated cells and is pooled from three independent experiments. Error bars represent the SD. b The cells used in (a) were fixed with methanol and restained with a fluorescent (FITC) Fab anti-human secondary antibody. The samples were assessed for human antibody (opsonin) binding to the Spike-beads using flow cytometry. The data are from three independent experiments. Error bars represent the SD. 
different doses of neutralizing and non-neutralizing antibodies in an experimental animal infection model (Fig. 6a). We infected humanized ACE2 mice intranasally with 105 PFU (SARS-CoV-2; Wuhan strain from Swedish isolate). As a treatment model, we administered our monoclonal antibodies intraperitoneally a day after infection. Based on previous experience, we used the pseudovirus neutralization data (Fig. 4c) to calculate a protective dose in a prophylactic model (100 $\mu \mathrm{g}$ for Ab59). To test the effects of high dose administration, Ab59 was given at five times the calculated protective dose. For Ab94, we chose the same dose that would be considered protective for Ab59 (100 $\mu \mathrm{g})$, as well as a higher dose $(250 \mu \mathrm{g})$, which would be equivalent to the protective Ab59 dose based on the lower affinity of Ab94 ( 2.5 times lower, Fig. 2C and Fig. 5B). Interestingly, the best-protected animal group (lower weight loss) was the one where the animals were treated with the equivalent to a protective dose of our non-neutralizing yet opsonic Ab94 (Fig. 6b). Unexpectedly, the animals treated with a low dose of Ab59 fared better than the ones with the high dose, which had the worst outcome (more pronounced weight loss) among the treated groups. The low dose of Ab94 offered negligible improvement compared to untreated animals (Fig. $6 \mathrm{~b})$. The animal data indicate that too high doses of neutralizing antibodies are not beneficial in a treatment model and that non-neutralizing antibodies can offer protection to SARS-CoV-2 infection.

\section{Discussion}

In this report, we present data on antibody modulation of Spike-monocyte interactions. To the best of our knowledge, only one previously published report showed Spike-bead phagocytosis after opsonization with 50\% heat-inactivated serum and a 16 hours incubation of beads with THP-1 cells (22). We believe that the data from our experiments are more representative of the first few events after Spike-monocyte contact. Phagocytosis of small particles such as virions is a process that takes minutes, not hours (27). That is why we use shorter incubation times $(30 \mathrm{~min})$ and perform doseresponse analysis across varying plasma concentrations. The dose-response analysis we performed exposed an antibodymediated modulation of the Spike-monocyte interactions. It is important to elaborate on the concentrations we utilized, be it for plasma or monoclonal antibodies. For plasma, as tissues have a lower concentration of plasma proteins than whole blood, we used $1 \%$ as the highest concentration. As for the monoclonal antibody concentrations, we used 100 $\mu \mathrm{g} / \mathrm{ml}$ as the highest concentration because it is roughly $1 \%$ of the antibody concentration present in plasma (10 $\mathrm{mg} / \mathrm{ml}$ ). Even though most of the experiments in this study are performed in vitro, we believe the effects we observe on phagocytosis could also be relevant in vivo, as the modulation effects occur already at relatively low antibody concentrations and would thus cover many physiological niches and scenarios.
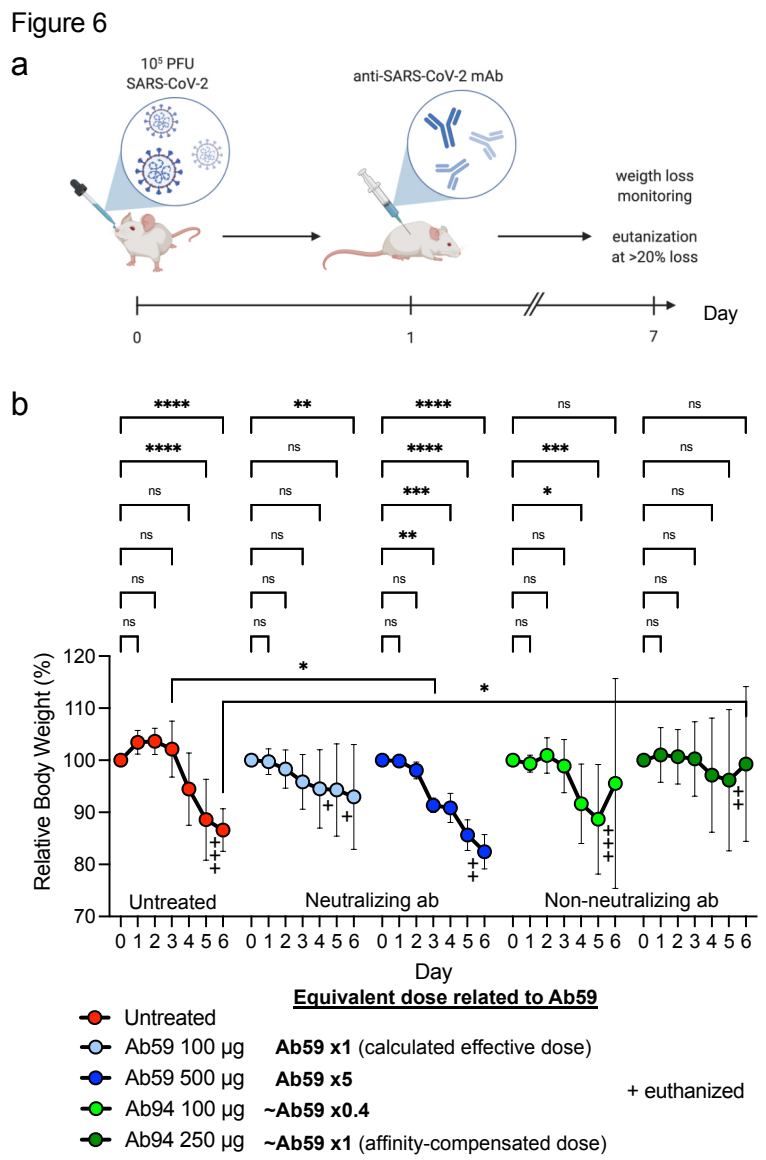

Fig. 6. Non-neutralizing antibodies can protect against SARS-CoV-2 infection. aHumanized ACE2 mice were infected intranasally with SARS-CoV-2 (Wuhan strain). One day after infection, the animals ( $N=7$ per group) were treated intraperitoneally with antibodies. Relative body weights were recorded and tabulated. b Body weights relative to each individual mouse over the time course of viral infection and treatment. Error bars represent the SD. Statistical significance was assessed using two-way ANOVA with Dunnett's multiple comparison correction both within each treatment group and across the groups for each day. ${ }^{*}$ denotes $p 0.05,{ }^{* *}$ for $p$ $0.01,{ }^{* * *}$ for $p 0.001$ and ${ }^{* * * *}$ for $p 0.0001$ ).

That an increased binding of antibodies to a prey results in reduced or blocked phagocytosis is in stark contrast to what is typically expected (28). It cannot be explained by specific monoclonal interactions, as it is seen across diverse monoclonals as well as in convalescent polyclonal samples. This block in phagocytosis is only related to Spike protein. A combination of known mechanisms could potentially explain how SARS-CoV-2 could avoid phagocytosis using Spike protein. Bivalent trans-binding of antibodies is known to promote virion phagocytosis (29), where antigens are cross-linked depending on their density at the surface. Spike protein density on SARS-CoV-2 varies (30), and is increased with the D614G mutation (31). An increase in Spike antibody levels would lead to a competition of epitope binding, ultimately favoring the switch from bivalent trans-binding to monovalent binding, potentially leading to a reduction in phagocytosis. A synergistic mechanism could further aid SARS-CoV-2. Antigen height (especially below $10 \mathrm{~nm}$ ) is important for efficient phagocytosis (32), and most likely, a consistent antigen height is beneficial as well. Besides altering its density, SARS-CoV-2 also appears to be able to 
dramatically change the Spike protein conformation, where some proteins stand up vertically from the surface, and others are tilted down horizontally (30). At high anti-Spike levels, this would present an approaching phagocyte with a monovalently opsonized, irregular surface with variable antigen height ( $15-25 \mathrm{~nm}$ ), making the interaction difficult. In contrast, at low anti-Spike levels, the antibodies would be able to clasp Spike proteins in a bivalent, upright manner, presenting the phagocyte with a coherently opsonized surface at an effectively low antigen height. Careful mechanistic studies are needed to test this hypothesis.

How does the concentration-dependent phagocytosis modulation translate into an infection model? We utilized our anti-Spike antibodies as a therapeutic regimen in our animal infection. This creates a scenario where the mouse is already fighting the infection before therapy gets administered. The requirements, therefore, on therapeutic antibodies are higher than on prophylactic ones. When comparing the 100- $\mu$ g dose of Ab59 and Ab94 (equivalent to 2.5 times lower binding affinity), we noticed that Ab59 showed better protection than the latter antibody. This could be attributed to either the neutralizing activity of Ab59, which Ab94 lacks, or the lower effective dose, given the lower Spike binding affinity of Ab94. Consistent with our data on phagocytosis (Fig. 5), animals treated with the high dose of Ab59 (500

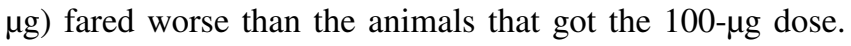
Interestingly, the animals that got the affinity-corrected dose for Ab94 (250 $\mu \mathrm{g}$, equivalent to $100 \mu \mathrm{g}$ of Ab59 in terms of binding affinity) fared the best in our cohort. The animal infection data on Ab94 protecting the mice is, most importantly, congruent with the phagocytosis data, indicating a role in infection management for non-neutralizing antibodies. In future studies, it remains to be established how infections would proceed in animals treated with an excessive dose of non-neutralizing antibodies. Our animal experiments show that monoclonal antibodies could be viable therapeutics even if they lack neutralizing potential. This is an interesting discovery that, to the best of our knowledge, has not been shown before. Additionally, the dose variation data from Ab59-treated groups reflects the data we have presented in the concentration-dependent modulation of Spike phagocytosis section. These results may explain the clinical findings seen in antibody therapy trials in the sense that having low or excessive dosage of antibodies offers no clinical benefit (33).

It is widely accepted that a strong positive correlation exists between COVID19 disease severity and antibody titers (34, 35, 36, 37). High antibody titers are generally associated with severe disease and hospitalization. The high titers are thought to be a consequence of the severe infection. Our results pose a new question: could the high anti-Spike titers seen in hospitalized patients instead (at least partially) contribute to the immune dysregulation and worsening patient outcomes? These questions are relevant in the light of the FDA's recommendation not to use monoclonal antibodies in hospitalized COVID19 patients (and who are seropositive) due to possible worsening of symptoms $(3,5)$. At the same time, it is important to note that convalescent plasma treatment for COVID19 was shown to be neither beneficial nor detrimental (38). Overall, the results presented in this study highlight a concentration-dependent modulation of phagocytosis by anti-Spike antibodies. This modulation phenomenon might help explain the unclear clinical benefit seen with monoclonal antibody treatment for COVID19. This modulation is seen in patient material and translates well to animal infection experiments. This opens several avenues for further experimentation. The biophysical mechanism underlying the antibody-mediated phagocytic modulation is an exciting topic to pursue, as are the bridging immune steps between phagocytosis and animal protection.

\section{Methods}

Cell culture, transfection, and protein production THP-1 cells were maintained in RPMI medium supplemented with $10 \mathrm{mM}$ L-Glutamine and $10 \%$ fetal bovine serum (FBS). The cells were split kept at a density between $5 \times 10^{5}$ and $10^{6}$ cells $/ \mathrm{ml}$. The cells were split when they reached a density of $10^{6}$ cells $/ \mathrm{ml}$, down to $5 \times 10^{5}$ cells $/ \mathrm{ml}$. HEK293 cells (Sigma Aldrich 12022001-1VL) were maintained in DMEM supplemented with L-glutamine and 10\% FBS. The cells were kept at $90 \%$ confluence and were not allowed to grow past passage 20. The plasmids for the 96 antibodies were aliquoted into 96 well plates. The cells to be transfected were grown in 24-well plates, with $500 \mu \mathrm{l}$ of tissue culture medium. The plasmids were transfected into adherent HEK293 cells using the PEI method (39). The day after transfection the cell culture supernatant media was replaced with serum-free OptiMEM medium for 2 extra days. The supernatants containing the antibodies were distributed also in 96 well plates and stored for maximum one week for experimental use. HEK293 cells constitutively expressing the ACE2 receptor were acquired from BEI resources (NR52511). They were maintained in DMEM supplemented with L- glutamine and 10\% FBS for a maximum of 12 passages before being discarded. Expi293F suspension cells were purchased from Gibco (ThermoFisher) and routinely cultured in $125 \mathrm{ml}$ Erlenmeyer flasks (Nalgene) in $30 \mathrm{ml}$ Expi293 medium (Gibco) in an Eppendorf s4li shaker incubator at $37^{\circ} \mathrm{C}, 8 \% \mathrm{CO} 2,120 \mathrm{rpm}$. Cells were passaged and split to a density of $0.5 \times 106$ cells $/ \mathrm{ml}$ every 3 to 4 days. The day before transfection, the cells were seeded at a density of $2 \times 10^{6}$ cells $/ \mathrm{ml}$. The next day, cells were seeded at $7.5 \times 10^{7}$ cells in $25.5 \mathrm{ml}$ Expi293 medium. The transient transfection was carried out using $100 \mu \mathrm{l}$ of Expifectamine (Gibco) according to the manufacturer's instructions. For Spike protein production, we used $40 \mu \mathrm{g}$ of the Spike CS/PP plasmid (generously donated by Dr. Florian Krammer's lab). For antibody production, $20 \mu \mathrm{g}$ of plasmids for the heavy and light chain was used, respectively. For all plasmids, 16 hours after transfection, $150 \mu$ of enhancer 1 and 1.5 $\mathrm{ml}$ of enhancer 2 (Expifectamine transfection kit, Gibco) were added and cells cultured for an additional 3 days. The cells were then pelleted at $400 \mathrm{xg}, 5 \mathrm{~min}$, RT and the 
supernatant transferred to new tubes. Magne Protein $\mathrm{G}$ beads (Promega) were used to purify the antibodies according to the manufacturer's instructions.

Antibody phage selections SARS-CoV-2 Spike RBDspecific $\mathrm{scFv}$ were selected by phage display technology from a human synthetic scFv library(40), similar in design and construction to previously reported(41). Briefly, selection of specific binders was performed through a process similar to the one described in the past(41) using biotinylated proteins SARS-CoV-2 S1 protein, His, Avitag ${ }^{\mathrm{TM}}$ (ACRO Biosystems, S1N-C82E8) and SARS-CoV-2 Spike RBD, His, Avitag ${ }^{\mathrm{TM}}$ (ACRO Biosystems, SPD-C82E9) immobilized on paramagnetic beads (Dynabeads M-280 streptavidin; Invitrogen Dynal AS, Oslo, Norway) as target antigen. Phagemid DNA from the third and fourth rounds of phage selection was isolated (Plasmid Miniprep kit, Qiagen) and the genes encoding $\mathrm{scFv}$ fragments were ligated into an in-house constructed screening vector providing the secreted $\mathrm{scFv}$ with a triple-FLAG tag and a hexahistidine (His6) tag at the C-terminus. The constructs were subsequently transformed into TOP10 E. coli and individual, soluble scFv were produced as described elsewhere (41). Binding of individual selected $\mathrm{scFv}$ was initially assessed by ELISA against biotinylated antigen. Seven scFvs specific for RBD isolated this way were used to map relative epitope location of human IgG. The scFvs bind four epitopes on RBD, and two of them (A03-D03 and E01-C09) also interfere with the RBD-ACE2 interaction (data not shown).

COVID19 patient samples and $B$ cell isolation For the spike-THP-1 association experiments, 20 patients who had mild, moderate or severe COVID19 were asked to donate blood 6 weeks after infection diagnosis. Patients were classified into mild, moderate and severe COVID19 based on supportive respiratory treatment. Patients with mild COVID19 did not require oxygen treatment. Patients with moderate COVID-19 required supplementary oxygen support wheras patients with severe COVID-19 required non-invasive ventilation or high-flow nasal cannula oxygen therapy. All participants gave written informed consent to participate in the study which was approved by the Swedish ethical review authority (2020/01747). Blood was drawn in citrated tubes and plasma was stored in the $-80{ }^{\circ} \mathrm{C}$. For B cell isolation and antibody discovery, patients convalescing after severe COVID19 infection donated blood 6 weeks after discharge from the hospital. Thirtyml of blood were drawn into citrated tubes and the B cells were directly isolated using Rosettesep B (according to the manufacturor's instructions) and frozen at $-150^{\circ} \mathrm{C}$. B cells were harvested from 7 donors and were kept frozen until the sorting day when $10^{7}$ cells were thawed, pooled and prepared for baiting which was performed in PBS $+2 \%$ FBS. Spike protein (S1+S2 ECD-His Recombinant Protein) was purchased from SinoBiologicals (cat: $40589-V 08 B 1$ ) and was reconstituted to $1 \mathrm{mg} / \mathrm{ml}$ in PBS. Spike protein was conjugated to Alexafluor $647 \mathrm{mi}-$ croscale labeling kit (Invitrogen). The fluorescently labelled spike protein was incubated with the pooled B cells at a concentration of $0.5 \mu \mathrm{g} / \mathrm{ml}$ for 30 mins on ice. The cells were then washed with PBS, blocked in $2 \%$ BSA and stained with antibodies against CD19-PE (BD-555413), CD3-BV510 (BD-564713), IgG-BV421 (BD-562581) and a live/Dead Sytox stain. The cells were stained for $30 \mathrm{mins}$ on ice and were later washed and prepared for sorting. Bulk cell sorting was performed using a FACSAriaFusion sorter, where the gates were set using unstained and FMO-1 controls. 7000 spike-reactive cells were sorted into RPMI $+10 \%$ FBS and were transported immediately to the RNA-sequencing facility while on ice.

10X genomics sequencing and data analysis We performed 10X Genomics single-cell sequencing on the 7000 Spikereactive cells (Center for Translational Genomics facility, Lund University). Cellranger suite cellranger mkfastq was used for demultiplexing and cellranger vdj for generating $\mathrm{V}(\mathrm{D}) \mathrm{J}$ sequences and annotation. Once received, we collated the $\mathrm{V}(\mathrm{D}) \mathrm{J}$ regions from our antibodies of interest using the V-Loupe software (10X Genomics software platform). 96 antibodies were chosen based on their phylogenetic distribution and the light and heavy chain variable regions were cloned into an IgG1 expression vector (Twist Biosciences). The 192 antibody plasmids (light and heavy chain constructs) were transformed into chemically competent Mix'n'go E. coli (Zymo research, T3002) and minipreps were prepared from the resultant colonies. Multiple sequence alignment using the ClustalW algorithm was performed on the light chain sequences and the heavy chain sequences. Single-linkage clustering was performed using the sum of the Hamming distances between the aligned light chain and the heavy chain as the similarity metric.

Antibody reactivity screening For ELISA, $10 \mu \mathrm{g} / \mathrm{ml}$ of Spike protein diluted in PBS was immobilized onto ELISA wells overnight at $4^{\circ} \mathrm{C}$. The wells were washed with PBST and $100 \mu \mathrm{l}$ of antibody supernatants were added to each well. A negative control (normal human pooled serum) and positive control (COVID patient serum) were used at $10 \%$ dilutions (in PBS). After one hour of incubation at 37 ${ }^{\circ} \mathrm{C}$, the wells were washed and HRP-conjugated protein $\mathrm{G}$ (Biorad 1706425) was added and kept for one hour at $37^{\circ} \mathrm{C}$. The wells were finally washed and developed with $100 \mu \mathrm{l}$ developing reagent $(20 \mathrm{ml}$ Substrate buffer NaCitrate $\mathrm{pH} 4.5$ $+1 \mathrm{ml} \mathrm{ABTS}$ Peroxide substrate $+0.4 \mathrm{ml} \mathrm{H} 2 \mathrm{O} 2$ ). OD450 was recorded and plotted.

For bead-based screening, fluorescent (APC) streptavidin microsphere beads $(1 \mu \mathrm{m}$, Bangs Laboratories, Cat: CFR004) were used as Spike carriers. Spike protein was conjugated to biotin using the EZ-Link ${ }^{\mathrm{TM}}$ Micro Sulfo-NHSLC-Biotinylation Kit (Thermofischer; Cat: 21935). The biotinylated Spike protein was attached to the streptavidin microbeads according to the bead manufacturer's instructions. For antibody reactivity testing, the Spike-beads were blocked with 5\% BSA (in PBS) for 30 mins at $37^{\circ} \mathrm{C} .150 \mathrm{k}$ 
beads were then centrifuged and incubated with $1 \mu \mathrm{g} / \mathrm{ml}$ of antibody for one hour at $37^{\circ} \mathrm{C}$ in 96 -well plates. The beads were washed with PBS and a secondary Alexa Fluor 488 conjugated Fab -Fab antibody (Jackson laboratories) was used to develop fluorescent signal. After a 30 min incubation with the secondary antibodies, the beads were further washed and fluorescence was detected using a Beckman Coulter Cytoflex flow cytometer.

Spike-THP-1 association assays Spike-beads were opsonized with patient plasma or monoclonal antibodies at the specified concentrations for 30 minutes at $37^{\circ} \mathrm{C}$ in a $100 \mu \mathrm{l}$ volume in 96 well plates. The beads were then centrifuged and reconstituted in $50 \mu \mathrm{l}$ Sodium medium $(5.6 \mathrm{mM}$ glucose, $127 \mathrm{mM} \mathrm{NaCl}, 10.8 \mathrm{mM} \mathrm{KCl}, 2.4 \mathrm{mM}$ KH $2 \mathrm{PO} 4,1.6 \mathrm{mM}$ MgSO4, $10 \mathrm{mM}$ HEPES, $1.8 \mathrm{mM} \mathrm{CaCl} 2$; $\mathrm{pH}$ adjusted to 7.3 with $\mathrm{NaOH}$ ). THP-1 cells were washed twice with PBS and reconstituted in Sodium medium. Spike beads and THP- 1 cells were mixed at a ratio of 2 beads per THP- 1 cell, in a final volume of $100 \mu \mathrm{l}$ of Sodium medium. The suspension was mixed and cooled on ice for 5 minutes before incubating at $37^{\circ} \mathrm{C}$ in a shaking incubator for 30 minutes. The suspension was later cooled and analyzed via flow cytometry. Gating was first set on the cell population and the percentage of cells associated with beads (now fluorescent in the APC channel) was determined (Fig. 1a). After cell-spike reactivity analysis was done, the cells were centrifuged and fixed with methanol (for 10 minutes at room temperature). The cells were then washed and resuspended in PBS, awaiting further flow cytometry analysis. Gates were then changed to include all the beads in the APC-fluorescent channel (Fig. 1b, top right). For internalization analysis, Spike-beads were conjugated with pHrodo (FITC), an acid-sensitive dye that fluoresces in acidic environments. The beads were opsonized with different concentrations of antibodies and then interacted with THP-1 cells. Cells determined to be fluorescent in the APC and FITC channels by flow cytometry have had internalized as well as associated beads.

Pseudotyped virus neutralization assays Pseudotyped lentiviruses displaying the SARS-CoV-2 pandemic founder variant (Wu-Hu-1) packaging a firefly luciferase reporter gene were generated by the co-transfection of HEK293T cells using Lipofectamine 3000 (Invitrogen) per the manufacturer's protocols. Media was changed 12-16 hours after transfection, and pseudotyped viruses were harvested at 48and 72-hours post-transfection, clarified by centrifugation, and stored at $-80^{\circ} \mathrm{C}$ until use. Pseudotyped viruses sufficient to generate 50,000 relative light units (RLUs) were incubated with serial dilutions of antibodies for $60 \mathrm{~min}$ at $37^{\circ} \mathrm{C}$ in a 96-well plate, and then 15,000 HEK293T-hACE2 cells were added to each well. For these experiments, the HEK293T-hACE2 cell culture was supplemented with penicillin/streptomycin antibiotics to avoid contamination. Plates were incubated at $37^{\circ} \mathrm{C}$ for 48 hours, and luminescence was then measured using Bright-Glo (Promega) per the manufacturer's protocol, on a GM-2000 luminometer (Promega).

Bead-based neutralization assay HEK293T-ACE2 cells were seeded at density of 35,000 cells per well in a PolyD-Lysine coated flat bottom 96 well plate. The outer skirt wells were kept cell free and were filled with medium. The day of the experiment, Spike-beads were distributed to fresh 96 well plates, adding 700,000 beads/ well. The beads were opsonized with $100 \mu$ of antibody supernatants at $37^{\circ} \mathrm{C}$ for one hour. The beads were then resuspended by pipetting up and down and the bead/antibody mix was used to replace the medium on the HEK293T-ACE2 cells. The cells were incubated with beads for one hour at $37^{\circ} \mathrm{C}$. The cells then were washed three times with PBS and fixed with $4 \%$ paraformaldehyde at room temperature for 15 minutes. The cells were finally washed and prepared for imaging. Four images from the center of the field of each well in the 96-well plate were acquired using 10X magnification. The number of beads per field was automatically determined using the Nikon Jobs software. For each experiment, the average number of beads/quadrant per all 96 wells was calculated and used as a $100 \%$ reference. We chose to normalize our data internally this was because our hypothesis was that the majority of our antibodies would not be neutralizing. Data from four experiments were pooled and presented.

Animal experiments Forty-two nine-week old female K18 hACE2 (B6.Cg- $\mathrm{Tg}(\mathrm{K} 18-\mathrm{ACE} 2) 2 \mathrm{Prlmn} / \mathrm{J})$ mice were inoculated intranasally with $10^{5} \mathrm{PFU}$ of SARS-CoV-2 (Wuhan strain, isolate SARS-CoV-2/01/human/2020/SWE, sourced from the Swedish Health Authorities). These mice are transgenic and carry the human ACE2 gene, making them permissive to SARS-CoV-2 infection (Jackson laboratories). One day after infection, the mice were split into 6 groups of 7 mice and antibodies were administered in one single dose intraperitoneally. We opted for a therapeutic model because we wanted to test the therapeutic potential of our antibodies under the most robust conditions. The body weights of the mice were recorded daily and the animals were euthanized if they lost more than $20 \%$ of their body weights or showed a severe deterioration in health status. The infection proceeded for 7 days before the animals were euthanized. Blood, tissue and bronchoalveolar lavage were harvested and stored accordingly. All the animal experiments were performed under the approval of the regional animal experimental ethics committee in Stockholm (16765-2020).

Determination of IgG-antigen interaction kinetics Analysis of RBD-IgG reaction kinetics was performed on a MASS-16 biosensor instrument (Bruker, Hamburg, Germany). Anti-Human IgG (Fc) (Cytiva, Uppsala, Sweden) was diluted to $25 \mu \mathrm{g} / \mathrm{ml}$ in $10 \mathrm{mM}$ sodium acetate buffer pH 5 and immobilized on a High Capacity Amine Sensor chip (Bruker) (time of interaction: $7 \mathrm{~min}$; flow rate: 10 $\mu \mathrm{l} / \mathrm{min}$ ). S-protein-specific IgG was diluted in running buffer (Dulbecco's PBS (HyClone, South Logan, UT, USA) 
containing $0.01 \%$ Tween 20 ) and allowed to bind during a $90 \mathrm{~s}$ long injection (flow rate: $10 \mu \mathrm{l} / \mathrm{min}$ ). Its capture level was set to be below 140 RU. The antigen (SARS-CoV-2 RBD (SinoBiological, Beijing, China; product number $40592-\mathrm{V} 08 \mathrm{H})$ at $0.7-180 \mathrm{nM}$ or Spike protein at $0.4-90$ $\mathrm{nM}$ in running buffer) was subsequently injected (time of interaction: $2 \mathrm{~min}$; flow rate: $30 \mu \mathrm{l} / \mathrm{min}$ ). Dissociation was subsequently allowed to proceed for 5-15 min. The sensor chip was regenerated by treatment with $3 \mathrm{M}$ magnesium chloride solution (Cytiva). All interactions were performed at $25^{\circ} \mathrm{C}$. Apparent reaction rate kinetics was determined using a Langmuir 1:1 model using the Sierra Analyser software version 3.4.3 (Bruker).

\section{Competition ELISA to define relative epitope location} High binding polystyrene 96-well plates (Corning Inc., Corning, NY, USA ) were coated with $2 \mu \mathrm{g} / \mathrm{ml}$ streptavidin (Thermo Fisher Scientific, Waltham, MA, USA) diluted in Dulbecco's PBS (HyClone, South Logan, UT, USA) over night at $+4^{\circ} \mathrm{C}$. On the following day the plate was washed and subsequently incubated for $30 \mathrm{~min}$ with $30 \mu \mathrm{l}$ $30 \mathrm{nM}$ biotinylated SARS-CoV-2 RBD (SinoBiological; product number:40592-V27H-B) diluted in Dulbecco's PBS containing $0.05 \%$ Tween 20 and $0.5 \%$ fish gelatine (Sigma Aldrich, St. Louis, MO, USA) (assay buffer). After washing the immobilized antigen was preincubated for 40 minutes at room temperature with $30 \mu \mathrm{l}$ assay buffer or assay buffer containing $4.8 \mathrm{pmol}$ IgG. Subsequently, $10 \mu \mathrm{l}$ of assay buffer or assay buffer containing $4.8 \mathrm{pmol} \mathrm{scFv}$ was added to each well. After 1 hour incubation at room temperature the wells were washed and bound $\mathrm{scFv}$ was detected by incubation for 40 minutes at room temperature with peroxidase labelled monoclonal anti-FLAG ${ }^{\circledR}$ M2 antibody (Sigma Aldrich (30 $\mu \mathrm{l}$ diluted $1 / 4000$ in assay buffer) and development using 1-Step ${ }^{\mathrm{TM}}$ Ultra TMB-ELISA Substrate Solution (Thermo Fisher Scientific).

Surface plasmon resonance studies to assess IgGspecificity The ability of IgG to interfere with the binding of SARS-CoV-2 RBD to its receptor, Angiotensin-Converting Enzyme 2 (ACE2) was examined by surface plasmon resonance-based detection in real time using a MASS-16 instrument (Bruker, Hamburg, Germany). The spots on a High Capacity Amine Sensor chip (Bruker) were immobilized with streptavidin (ThermoFisher Scientific, Waltham, MA, USA) $(50 \mu \mathrm{g} / \mathrm{ml}$ diluted in $10 \mathrm{mM}$ sodium acetate buffer $\mathrm{pH}$ 5.0; flow rate: $10 \mu \mathrm{l} / \mathrm{min}$; time of immobilization: $6 \mathrm{~min}$ ) to a level of approximately $1000 \mathrm{RU}$. Subsequently $50 \mathrm{nM}$ biotinylated ACE2 (SinoBiological, Beijing, Shina; product number: 10108-H08H-B) was immobilized onto the chip's A spots (flow rate: $10 \mu \mathrm{l} / \mathrm{s}$; time of binding: 2 min) while B spots were used as reference spots without ACE-2. 40 and $26 \mathrm{nM}$ Receptor Binding Domain (RBD) was pre-incubated with $200 \mathrm{nM} \mathrm{IgG}$ diluted in Dulbecco's PBS (HyClone, South Logan, UT, USA) containing 0.01\% Tween 20. The mixtures were injected over the sensor chip for $2 \mathrm{~min}$, followed by a $6 \mathrm{~min}$ dissociation phase (flow rate:
$30 \mu \mathrm{l} / \mathrm{min}$ ). The sensor chip was regenerated by treatment with $1 \mathrm{M}$ magnesium chloride solution (Sigma Aldrich, St Louis, MO, USA).

Binding of IgG to different mutated versions of SARS-CoV-2 was examined by a surface plasmon resonance assay. A High Capacity Amine Sensor chip (Bruker) was immobilized with $\mathrm{F}(\mathrm{ab}$ ') Goat Anti-Human IgG, $\mathrm{Fc} \gamma$ fragment specific (Jackson, Ely, UK) at $50 \mu \mathrm{g} / \mathrm{ml}$ in $10 \mathrm{mM}$ sodium acetate buffer $\mathrm{pH} 5$ (time of interaction: $7 \mathrm{~min}$; flow rate: $10 \mu \mathrm{l} / \mathrm{min}$ ). Antibodies were diluted in Dulbecco's PBS (HyClone, South Logan, UT, USA) containing $0.01 \%$ Tween 20 and injected over the surface for 2 minutes at $10 \mu \mathrm{L} / \mathrm{min}$. The antigens, produced in HEK293 cells, were obtained from SinoBiological (Beijing, China; product numbers: SARS-CoV-2 Spike RBD: 40592-V08H; SARS-CoV-2 Spike RBD-N501Y: 40592-V08H82; SARS-CoV-2 Spike RBD-E484K: 40592-V08H84; SARS-CoV-2 Spike RBDK417N, E484K, N501Y: 40592-V08H85; SARS-CoV-2 Spike S1 HV69-70 deletion, Y144 deletion, N501Y, A570D, D614G, P681H: 40591-V08H12). All proteins were diluted to $50 \mathrm{nM}$ in Dulbecco's PBS containing $0.01 \%$ Tween 20 and injected over the surface (time of interaction: 2 minutes; flow rate: $30 \mu \mathrm{l} / \mathrm{min}$ ) followed by a dissociation phase of 6 minutes. After each cycle the surface was regenerated with $10 \mathrm{mM}$ glycin $\mathrm{pH} 2.2$ containing $30 \mathrm{mM} \mathrm{HCl}$.

Crosslinking of antibodies to Spike protein For the crosslinking of the antibodies to the Spike protein, $2 \mathrm{uG}$ of each antibody was separately cross-linked to $2 \mathrm{uG}$ of the Spike protein (Sino Biological Inc. 40589-V08H4 LC14SE2504, Recombinant SARS CoV-2 (1029-nCoV) Spike), as previously described (42). Briefly, the proteins were allowed to bind to each other in $50 \mathrm{uL}$ of $1 \mathrm{xPBS}$, $\mathrm{pH} 7.4$ at $37{ }^{\circ} \mathrm{C}, 500 \mathrm{rpm}, 15 \mathrm{~min}$. Heavy/light disuccinimidylsuberate (DSS; DSS-H12/D12, Creative Molecules Inc.) resuspended in dimethylformamide (DMF) was added to final concentrations 250 and $500 \mu \mathrm{M}$ and incubated for a further of $60 \mathrm{~min}$ at $37{ }^{\circ} \mathrm{C}, 800 \mathrm{rpm}$. The crosslinking reaction was quenched with a final concentration of $50 \mathrm{mM}$ ammonium bicarbonate at $37^{\circ} \mathrm{C}, 800 \mathrm{rpm}, 15 \mathrm{~min}$.

Sample preparation for MS The crosslinked samples mixed with $8 \mathrm{M}$ urea and $100 \mathrm{mM}$ ammonium bicarbonate, and the cysteine bonds were reduced with $5 \mathrm{mM}$ TCEP $\left(37^{\circ} \mathrm{C}\right.$ for $2 \mathrm{~h}, 800 \mathrm{rpm}$ ) and alkylated with $10 \mathrm{mM}$ iodoacetamide $\left(22{ }^{\circ} \mathrm{C}\right.$ for $30 \mathrm{~min}$, in the dark). The proteins were first digested with $1 \mu \mathrm{g}$ of sequencing grade lysyl endopeptidase (Wako Chemicals) $\left(37^{\circ} \mathrm{C}, 800 \mathrm{rpm}, 2 \mathrm{~h}\right)$. The samples were diluted with $100 \mathrm{mM}$ ammonium bicarbonate to a final urea concentration of $1.5 \mathrm{M}$, and $1 \mu \mathrm{g}$ sequencing grade trypsin (Promega) was added for further protein digestion $\left(37^{\circ} \mathrm{C}\right.$, $800 \mathrm{rpm}, 18 \mathrm{~h}$ ). Samples were acidified (to a final $\mathrm{pH}$ 3.0) with $10 \%$ formic acid, and the peptides purified with $\mathrm{C} 18$ reverse phase spin columns according to the manufacturer's instructions (Macrospin columns, Harvard Apparatus). Peptides were dried in a speedvac and reconstituted in $2 \%$ 
bioRxiv preprint doi: https://doi.org/10.1101/2021.10.14.464464; this version posted October 15, 2021. The copyright holder for this preprint (which was not certified by peer review) is the author/funder, who has granted bioRxiv a license to display the preprint in perpetuity. It is made available under aCC-BY-NC-ND 4.0 International license.

acetonitrile, $0.2 \%$ formic acid prior to mass spectrometric analyses.

\section{Liquid chromatography tandem mass spectrometry} (LC-MS/MS) All peptide analyses were performed on Q Exactive HF-X mass spectrometer (Thermo Scientific) connected to an EASY-nLC 1200 ultra-high-performance liquid chromatography system (Thermo Scientific). Peptides were loaded onto an Acclaim PepMap $100(75 \mu \mathrm{m}$ x $2 \mathrm{~cm}) \mathrm{C} 18$ (3 $\mu \mathrm{m}, 100 \AA$ A) pre-column and separated on an EASY-Spray column (Thermo Scientific; ID $75 \mu \mathrm{m}$ x $50 \mathrm{~cm}$, column temperature $45^{\circ} \mathrm{C}$ ) operated at a constant pressure of 800 bar. A linear gradient from 4 to $45 \%$ of $80 \%$ acetonitrile in aqueous $0.1 \%$ formic acid was run for $65 \mathrm{~min}$ at a flow rate of $350 \mathrm{nl}$ min-1. One full MS scan (resolution $60000 @ 200$ $\mathrm{m} / \mathrm{z}$; mass range 390-1 210m/z) was followed by MS/MS scans (resolution 15000 @ 200 m/z) of the 15 most abundant ion signals. The precursor ions were isolated with $2 \mathrm{~m} / \mathrm{z}$ isolation width and fragmented using HCD at a normalized collision energy of 30. Charge state screening was enabled, and precursors with an unknown charge state and a charge state of 1 were rejected. The dynamic exclusion window was set to $10 \mathrm{~s}$. The automatic gain control was set to $3 \mathrm{e} 6$ and 1e5 for MS and MS/MS with ion accumulation times of $110 \mathrm{~ms}$ and $60 \mathrm{~ms}$, respectively. The intensity threshold for precursor ion selection was set to $1.7 \mathrm{e}^{4}$.

Author contributions Conceptualization: WB, VWH, RW, $\mathrm{JM}, \mathrm{LM}, \mathrm{MO}, \mathrm{MR}$, and PN. Experimentation and data analysis: WB, SW, MS, AB, UH, OL, HK, MG, MW, EE, LH, OA, JKA, TH. Writing original draft: WB and PN. All authors contributed to reading and editing the final manuscript.

Acknowledgements WB, LM, JM and PN are funded by the Knut and Alice Wallenberg Foundation. TH and equipment were funded by IngaBritt och Arne Lundbergs Forskningsstiftelse. WB, MO, JM, MR, and PN were funded by grants from the SciLifeLab National COVID-19 Research Program, financed by the Knut and Alice Wallenberg Foundation. WB were funded by the Royal Physiographic Society. HK were funded by Swiss National Science Foundation (grant no. P2ZHP3_191289). We thank Åsa Petersson for help with flow sorting and Berit Olofsson for technical assistance. We thank Benjamin Murrell and Daniel Sheward at the Karolinska Institutet for help with the pseudovirus neutralization assay. We thank Ali Mirazimi at the Public Health Agency of Sweden and Karolinska Institutet, for providing virus for the animal infection experiments performed. We thank the Lund University Bioimaging Centre (LBIC) for use of fluorescence microscopes.

\section{Conflicts of interest}

\section{References}

1. Palivizumab, a humanized respiratory syncytial virus monoclonal antibody, reduces hospitalization from respiratory syncytial virus infection in high-risk infants. Pediatrics, 102(3):531537, sep 1998.

2. Sabue Mulangu, Lori E Dodd, Richard T Davey, Olivier Tshiani Mbaya, Michael Proschan, Daniel Mukadi, Mariano Lusakibanza Manzo, Didier Nzolo, Antoine Tshomba Oloma, Augustin Ibanda, Rosine Ali, Sinaré Coulibaly, Adam C Levine, Rebecca Grais, Janet Diaz, H Clifford Lane, Jean-Jacques Muyembe-Tamfum, PALM Writing Group, Billy Sivahera, Modet Camara, Richard Kojan, Robert Walker, Bonnie Dighero-Kemp, Huyen Cao, Philippe Mukumbayi, Placide Mbala-Kingebeni, Steve Ahuka, Sarah Albert, Tyler Bonnett, lan Crozier, Michael Duvenhage, Calvin Proffitt, Marc Teitelbaum, Thomas Moench, Jamila Aboulhab, Kevin Barrett, Kelly Cahill, Katherine Cone, Risa Eckes, Lisa Hensley, Betsey Herpin, Elizabeth Higgs, Julie Ledgerwood, Jerome Pierson, Mary Smolskis, Ydrissa Sow, John Tierney, Sumathi Sivapalasingam, Wendy Holman, Nikki Gettinger, David Vallée, Jacqueline Nordwall, and PALM Consortium Study Team. A randomized, controlled trial of ebola virus disease therapeutics. The New England Journal of Medicine, 381(24):22932303, dec 2019.

3. FDA. FACT SHEET FOR HEALTH CARE PROVIDERS EMERGENCY USE AUTHORIZATION (EUA) OF REGEN-COVTM (casirivimab with imdevimab), 2021.

4. Robert L Gottlieb, Ajay Nirula, Peter Chen, Joseph Boscia, Barry Heller, Jason Morris, Gregory Huhn, Jose Cardona, Bharat Mocherla, Valentina Stosor, Imad Shawa, Princy Kumar, Andrew C Adams, Jacob Van Naarden, Kenneth L Custer, Michael Durante, Gerard Oakley, Andrew E Schade, Timothy R Holzer, Philip J Ebert, Richard E Higgs, Nicole L Kallewaard, Janelle Sabo, Dipak R Patel, Paul Klekotka, Lei Shen, and Daniel M Skovronsky. Effect of bamlanivimab as monotherapy or in combination with etesevimab on viral load in patients with mild to moderate COVID-19: A randomized clinical trial. The Journal of the American Medical Association, 325(7):632-644, feb 2021.

5. FDA. EMERGENCY USE AUTHORIZATION (EUA) OF BAMLANIVIMAB AND ETESEVIMAB AUTHORIZED USE, 2021.

6. Peter C Taylor, Andrew C Adams, Matthew M Hufford, Inmaculada de la Torre, Kevin Winthrop, and Robert $L$ Gottlieb. Neutralizing monoclonal antibodies for treatment of COVID-19. Nature Reviews. Immunology, 21(6):382-393, jun 2021.

7. Yan Wu, Feiran Wang, Chenguang Shen, Weiyu Peng, Delin Li, Cheng Zhao, Zhaohui Li, Shihua Li, Yuhai Bi, Yang Yang, Yuhuan Gong, Haixia Xiao, Zheng Fan, Shuguang Tan, Guizhen Wu, Wenjie Tan, Xuancheng Lu, Changfa Fan, Qihui Wang, Yingxia Liu, Chen Zhang, Jianxun Qi, George Fu Gao, Feng Gao, and Lei Liu. A noncompeting pair of human neutralizing antibodies block COVID-19 virus binding to its receptor ACE2. Science, 368(6496):1274-1278, jun 2020.

8. Yunlong Cao, Bin Su, Xianghua Guo, Wenjie Sun, Yongqiang Deng, Linlin Bao, Qinyu Zhu, Xu Zhang, Yinghui Zheng, Chenyang Geng, Xiaoran Chai, Runsheng He, Xiaofeng Li, Qi Lv, Hua Zhu, Wei Deng, Yanfeng Xu, Yanjun Wang, Luxin Qiao, Yafang Tan, Liyang Song, Guopeng Wang, Xiaoxia Du, Ning Gao, Jiangning Liu, Junyu Xiao, Xiao-Dong Su, Zongmin Du, Yingmei Feng, Chuan Qin, Chengfeng Qin, Ronghua Jin, and X Sunney Xie. Potent neutralizing antibodies against SARS-CoV-2 identified by high-throughput single-cell sequencing of convalescent patients' b cells. Cell, 182(1):73-84.e16, jul 2020.

9. Bin Ju, Qi Zhang, Jiwan Ge, Ruoke Wang, Jing Sun, Xiangyang Ge, Jiazhen Yu, Sisi Shan, Bing Zhou, Shuo Song, Xian Tang, Jinfang Yu, Jun Lan, Jing Yuan, Haiyan Wang, Juanjuan Zhao, Shuye Zhang, Youchun Wang, Xuanling Shi, Lei Liu, Jincun Zhao, Xinquan Wang, Zheng Zhang, and Lingi Zhang. Human neutralizing antibodies elicited by SARS-CoV-2 infection. Nature, 584(7819):115-119, aug 2020.

10. Shuang Wang, Yun Peng, Rongjuan Wang, Shasha Jiao, Min Wang, Weijin Huang, Chao Shan, Wen Jiang, Zepeng Li, Chunying Gu, Ben Chen, Xue Hu, Yanfeng Yao, Juan Min, Huajun Zhang, Ying Chen, Ge Gao, Peipei Tang, Gang Li, An Wang, Lan Wang, Jinchao Zhang, Shuo Chen, Xun Gui, Zhiming Yuan, and Datao Liu. Characterization of neutralizing antibody with prophylactic and therapeutic efficacy against SARS-CoV-2 in rhesus monkeys. Nature Communications, 11(1):5752, nov 2020.

11. Seiya Yamayoshi, Atsuhiro Yasuhara, Mutsumi Ito, Osamu Akasaka, Morio Nakamura, Ichiro Nakachi, Michiko Koga, Keiko Mitamura, Kazuma Yagi, Kenji Maeda, Hideaki Kato, Masanori Nojima, David Pattinson, Takayuki Ogura, Rie Baba, Kensuke Fujita, Hiroyuki Nagai, Shinya Yamamoto, Makoto Saito, Eisuke Adachi, Junichi Ochi, Shin-Ichiro Hattori, Tetsuya Suzuki, Yusuke Miyazato, Shiho Chiba, Moe Okuda, Jurika Murakami, Taiki Hamabata, Kiyoko Iwatsuki-Horimoto, Hideaki Nakajima, Hiroaki Mitsuya, Norio Omagari, Norio Sugaya, Hiroshi Yotsuyanagi, and Yoshihiro Kawaoka. Antibody titers against SARS-CoV-2 decline, but do not disappear for several months. EClinicalMedicine, 32:100734, feb 2021.

12. Donald N Forthal. Functions of antibodies. Microbiology spectrum, 2(4):1-17, aug 2014.

13. V C Huber, J M Lynch, D J Bucher, J Le, and D W Metzger. Fc receptor-mediated phagocytosis makes a significant contribution to clearance of influenza virus infections. Journal of Immunology, 166(12):7381-7388, jun 2001.

14. Haruo Fujisawa. Neutrophils play an essential role in cooperation with antibody in both protection against and recovery from pulmonary infection with influenza virus in mice. Journal of Virology, 82(6):2772-2783, mar 2008.

15. Shamus $P$ Keeler and Julie M Fox. Requirement of fc-fc gamma receptor interaction for antibody-based protection against emerging virus infections. Viruses, 13(6), may 2021.

16. Rekha Khandia, Ashok Munjal, Kuldeep Dhama, Kumaragurubaran Karthik, Ruchi Tiwari, Yashpal Singh Malik, Raj Kumar Singh, and Wanpen Chaicumpa. Modulation of dengue/zika virus pathogenicity by antibody-dependent enhancement and strategies to protect against enhancement in zika virus infection. Frontiers in immunology, 9:597, apr 2018.

17. Kumaragurubaran Karthik, Tuticorin Maragatham Alagesan Senthilkumar, Shanmugasundaram Udhayavel, and Gopal Dhinakar Raj. Role of antibody-dependent enhancement (ADE) in the virulence of SARS-CoV-2 and its mitigation strategies for the development of vaccines and immunotherapies to counter COVID-19. Human vaccines \& immunotherapeutics, 16(12):3055-3060, dec 2020.

18. Denis Y Logunov, Inna V Dolzhikova, Dmitry V Shcheblyakov, Amir I Tukhvatulin, Olga V Zubkova, Alina S Dzharullaeva, Anna V Kovyrshina, Nadezhda L Lubenets, Daria M Grousova, Alina S Erokhova, Andrei G Botikov, Fatima M Izhaeva, Olga Popova, Ta- 
bioRxiv preprint doi: https://doi.org/10.1101/2021.10.14.464464; this version posted October 15, 2021. The copyright holder for this preprint (which was not certified by peer review) is the author/funder, who has granted bioRxiv a license to display the preprint in perpetuity. It is made available under aCC-BY-NC-ND 4.0 International license.

tiana A Ozharovskaya, llias B Esmagambetov, Irina A Favorskaya, Denis I Zrelkin, Daria V Voronina, Dmitry N Shcherbinin, Alexander S Semikhin, Yana V Simakova, Elizaveta A Tokarskaya, Daria A Egorova, Maksim M Shmarov, Natalia A Nikitenko, Vladimir A Gushchin, Elena A Smolyarchuk, Sergey K Zyryanov, Sergei V Borisevich, Boris S Naroditsky, Alexander L Gintsburg, and Gam-COVID-Vac Vaccine Trial Group. Safety and efficacy of an rAd26 and rAd5 vector-based heterologous prime-boost COVID-19 vaccine: an interim analysis of a randomised controlled phase 3 trial in russia. The Lancet, 397(10275):671681 , feb 2021.

19. LR Baden, HM El Sahly, B Essink, K Kotloff, S Frey, R Novak, D Diemert, SA Spector, N Rouphael, CB Creech, J McGettigan, S Khetan, N Segall, J Solis, A Brosz, C Fierro, H Schwartz, K Neuzil, L Corey, P Gilbert, H Janes, D Follmann, M Marovich, J Mascola, L Polakowski, J Ledgerwood, BS Graham, H Bennett, R Pajon, C Knightly, B Leav, W Deng, H Zhou, S Han, M Ivarsson, J Miller, T Zaks, and COVE Study Group. Efficacy and safety of the mRNA-1273 SARS-CoV-2 vaccine. The New England Journal of Medicine, 384(5):403416, feb 2021.

20. Merryn Voysey, Sue Ann Costa Clemens, Shabir A Madhi, Lily Y Weckx, Pedro M Folegatti, Parvinder K Aley, Brian Angus, Vicky L Baillie, Shaun L Barnabas, Qasim E Bhorat, Sagida Bibi, Carmen Briner, Paola Cicconi, Andrea M Collins, Rachel Colin-Jones, Clare L Cutland, Thomas C Darton, Keertan Dheda, Christopher J A Duncan, Katherine R W Emary, Katie J Ewer, Lee Fairlie, Saul N Faust, Shuo Feng, Daniela M Ferreira, Adam Finn, Anna L Goodman, Catherine M Green, Christopher A Green, Paul T Heath, Catherine Hill, Helen Hill, Ian Hirsch, Susanne H C Hodgson, Alane Izu, Susan Jackson, Daniel Jenkin, Carina C D Joe, Simon Kerridge, Anthonet Koen, Gaurav Kwatra, Rajeka Lazarus, Alison M Lawrie, Alice Lelliott, Vincenzo Libri, Patrick J Lillie, Raburn Mallory, Ana V A Mendes, Eveline P Milan, Angela M Minassian, Alastair McGregor, Hazel Morrison, Yama F Mujadidi, Anusha Nana, Peter J O'Reilly, Sherman D Padayachee, Ana Pittella, Emma Plested, Katrina M Pollock, Maheshi N Ramasamy, Sarah Rhead, Alexandre V Schwarzbold, Nisha Singh, Andrew Smith, Rinn Song, Matthew D Snape, Eduardo Sprinz, Rebecca K Sutherland, Richard Tarrant, Emma C Thomson, M Estée Török, Mark Toshner, David P J Turner, Johan Vekemans, Tonya L Villafana, Marion E E Watson, Christopher J Williams, Alexander D Douglas, Adrian V S Hill, Teresa Lambe, Sarah C Gilbert, Andrew J Pollard, and Oxford COVID Vaccine Tria Group. Safety and efficacy of the ChAdOx1 nCoV-19 vaccine (AZD1222) against SARSCoV-2: an interim analysis of four randomised controlled trials in brazil, south africa, and the UK. The Lancet, 397(10269):99-111, jan 2021.

21. Fernando P Polack, Stephen J Thomas, Nicholas Kitchin, Judith Absalon, Alejandra Gurtman, Stephen Lockhart, John L Perez, Gonzalo Pérez Marc, Edson D Moreira, Cristiano Zerbini, Ruth Bailey, Kena A Swanson, Satrajit Roychoudhury, Kenneth Koury, Ping Li, Warren V Kalina, David Cooper, Robert W Frenck, Laura L Hammitt, Özlem Türeci, Haylene Nell, Axel Schaefer, Serhat Ünal, Dina B Tresnan, Susan Mather, Philip R Dormitzer, Uğur Şahin, Kathrin U Jansen, William C Gruber, and C4591001 Clinical Trial Group. Safety and efficacy of the BNT162b2 mRNA covid-19 vaccine. The New England Journal of Medicine, 383(27):2603-2615, dec 2020.

22. Carl A Pierce, Paula Preston-Hurlburt, Yile Dai, Clare Burn Aschner, Natalia Cheshenko, Benjamin Galen, Scott J Garforth, Natalia G Herrera, Rohit K Jangra, Nicholas C Morano, Erika Orner, Sharlene Sy, Kartik Chandran, James Dziura, Steven C Almo, Aaron Ring, Marla J Keller, Kevan C Herold, and Betsy C Herold. Immune responses to SARS-CoV-2 infection in hospitalized pediatric and adult patients. Science Translational Medicine, 12(564), oct 2020.

23. Galit Alter, Jingyou Yu, Jinyan Liu, Abishek Chandrashekar, Erica N Borducchi, Lisa $\mathrm{H}$ Tostanoski, Katherine McMahan, Catherine Jacob-Dolan, David R Martinez, Aiquan Chang, Tochi Anioke, Michelle Lifton, Joseph Nkolola, Kathryn E Stephenson, Caroline Atyeo, Sally Shin, Paul Fields, Ian Kaplan, Harlan Robins, Fatima Amanat, Florian Krammer, Ralph S Baric, Mathieu Le Gars, Jerald Sadoff, Anne Marit de Groot, Dirk Heerwegh, Frank Struyf Macaya Douoguih, Johan van Hoof, Hanneke Schuitemaker, and Dan H Barouch. Immunogenicity of ad26.COV2.s vaccine against SARS-CoV-2 variants in humans. Nature, 596(7871):268-272, aug 2021.

24. José María Díez, Carolina Romero, María Cruz, Peter Vandeberg, W. Keither Merritt, Edwards Pradenas, Benjamin Trinité, Julià Blanco, Bonaventura Clotet, Todd Willis, and Rodrigo Gajardo. Anti-SARS-CoV-2 hyperimmune immunoglobulin provides potent and robus neutralization capacity and antibody-dependent cellular cytotoxicity and phagocytosis induction through $\mathrm{n}$ and s proteins. BioRxiv, jun 2021.

25. Simon Hauri, Hamed Khakzad, Lotta Happonen, Johan Teleman, Johan Malmström, and Lars Malmström. Rapid determination of quaternary protein structures in complex biological samples. Nature Communications, 10(1):192, jan 2019

26. Julia Koehler Leman, Brian D Weitzner, Steven M Lewis, Jared Adolf-Bryfogle, Nawsad Alam, Rebecca F Alford, Melanie Aprahamian, David Baker, Kyle A Barlow, Patrick Barth, Benjamin Basanta, Brian J Bender, Kristin Blacklock, Jaume Bonet, Scott E Boyken, Phil Bradley, Chris Bystroff, Patrick Conway, Seth Cooper, Bruno E Correia, Brian Coventry, Rhiju Das, René M De Jong, Frank DiMaio, Lorna Dsilva, Roland Dunbrack, Alexander S Ford, Brandon Frenz, Darwin Y Fu, Caleb Geniesse, Lukasz Goldschmidt, Ragul Gowthaman, Jeffrey J Gray, Dominik Gront, Sharon Guffy, Scott Horowitz, Po-Ssu Huang, Thomas Huber, Tim M Jacobs, Jeliazko R Jeliazkov, David K Johnson, Kalli Kappel, John Karanicolas, Hamed Khakzad, Karen R Khar, Sagar D Khare, Firas Khatib, Alisa Khramushin, Indigo C King, Robert Kleffner, Brian Koepnick, Tanja Kortemme, Georg Kuenze, Brian Kuhlman, Daisuke Kuroda, Jason W Labonte, Jason K Lai, Gideon Lapidoth, Andrew Leaver-Fay, Steffen Lindert, Thomas Linsky, Nir London, Joseph H Lubin, Sergey Lyskov, Jack Maguire, Lars Malmström, Enrique Marcos, Orly Marcu, Nicholas A Marze, Jens Meiler, Rocco Moretti, Vikram Khipple Mulligan, Santrupti Nerli, Christoffer Norn, Shane Ó'Conchúir, Noah Ollikainen, Sergey Ovchinnikov, Michael S Pacella, Xingjie Pan, Hahnbeom Park, Ryan E Pavlovicz, Manasi Pethe, Brian G Pierce, Kala Bharath Pilla, Barak Raveh, P Douglas Renfrew, Shourya S Roy Burman, Aliza Rubenstein, Marion F Sauer, Andreas Scheck, William Schief, Ora Schueler-Furman, Yuval Sedan, Alexander M Sevy, Nikolaos G Sgourakis, Lei Shi, Justin B Siegel, Daniel-Adriano Silva, Shannon Smith, Yifan Song, Amelie Stein, Maria Szegedy, Frank D Teets, Summer B Thyme, Ray Yu-Ruei Wang, Andrew Watkins, Lior Zimmerman, and Richard Bonneau. Macromolecular modeling and design in rosetta: recent methods and frameworks. Nature Methods, 17(7):665-680, jul
2020.

27. Pontus Nordenfelt and Hans Tapper. Phagosome dynamics during phagocytosis by neutrophils. Journal of Leukocyte Biology, 90(2):271-284, aug 2011.

28. Therese de Neergaard, Martin Sundwall, Sebastian Wrighton, and Pontus Nordenfelt. Highsensitivity assessment of phagocytosis by persistent association-based normalization. Journal of Immunology, 206(1):214-224, jan 2021.

29. Joshua S Klein and Pamela J Bjorkman. Few and far between: how HIV may be evading antibody avidity. PLoS Pathogens, 6(5):e1000908, may 2010.

30. Zunlong Ke, Joaquin Oton, Kun Qu, Mirko Cortese, Vojtech Zila, Lesley McKeane, Takanori Nakane, Jasenko Zivanov, Christopher J Neufeldt, Berati Cerikan, John M Lu, Julia Peukes, Xiaoli Xiong, Hans-Georg Kräusslich, Sjors H W Scheres, Ralf Bartenschlager, and John A G Briggs. Structures and distributions of SARS-CoV-2 spike proteins on intact virions. Nature, 588(7838):498-502, dec 2020.

31. Lizhou Zhang, Cody B Jackson, Huihui Mou, Amrita Ojha, Haiyong Peng, Brian D Quinlan, Erumbi S Rangarajan, Andi Pan, Abigail Vanderheiden, Mehul S Suthar, Wenhui Li, Tina Izard, Christoph Rader, Michael Farzan, and Hyeryun Choe. SARS-CoV-2 spike-protein D614G mutation increases virion spike density and infectivity. Nature Communications, 11(1):6013, nov 2020.

32. Matthew H Bakalar, Aaron M Joffe, Eva M Schmid, Sungmin Son, Marija Podolski, and Daniel A Fletcher. Size-dependent segregation controls macrophage phagocytosis of antibody-opsonized targets. Cell, 174(1):131-142.e13, jun 2018.

33. Peter Chen, Ajay Nirula, Barry Heller, Robert L Gottlieb, Joseph Boscia, Jason Morris, Gregory Huhn, Jose Cardona, Bharat Mocherla, Valentina Stosor, Imad Shawa, Andrew C Adams, Jacob Van Naarden, Kenneth L Custer, Lei Shen, Michael Durante, Gerard Oakley, Andrew E Schade, Janelle Sabo, Dipak R Patel, Paul Klekotka, Daniel M Skovronsky, and BLAZE-1 Investigators. SARS-CoV-2 neutralizing antibody LY-CoV555 in outpatients with covid-19. The New England Journal of Medicine, 384(3):229-237, jan 2021.

34. Sabra L Klein, Andrew Pekosz, Han-Sol Park, Rebecca L Ursin, Janna R Shapiro, Sarah E Benner, Kirsten Littlefield, Swetha Kumar, Harnish Mukesh Naik, Michael J Betenbaugh, Ruchee Shrestha, Annie A Wu, Robert M Hughes, Imani Burgess, Patricio Caturegli, Oliver Laeyendecker, Thomas C Quinn, David Sullivan, Shmuel Shoham, Andrew D Redd, Evan M Bloch, Arturo Casadevall, and Aaron Ar Tobian. Sex, age, and hospitalization drive antibody responses in a COVID-19 convalescent plasma donor population. The Journal of Clinical Investigation, 130(11):6141-6150, nov 2020.

35. Wilfredo F Garcia-Beltran, Evan C Lam, Michael G Astudillo, Diane Yang, Tyler E Miller, Jared Feldman, Blake M Hauser, Timothy M Caradonna, Kiera L Clayton, Adam D Nitido, Mandakolathur R Murali, Galit Alter, Richelle C Charles, Anand Dighe, John A Branda, Jochen K Lennerz, Daniel Lingwood, Aaron G Schmidt, A John lafrate, and Alejandro B Balazs. COVID-19-neutralizing antibodies predict disease severity and survival. Cell, 184(2):476-488.e11, jan 2021

36. Quan-Xin Long, Bai-Zhong Liu, Hai-Jun Deng, Gui-Cheng Wu, Kun Deng, Yao-Kai Chen, Pu Liao, Jing-Fu Qiu, Yong Lin, Xue-Fei Cai, De-Qiang Wang, Yuan Hu, Ji-Hua Ren, Ni Tang, Yin-Yin Xu, Li-Hua Yu, Zhan Mo, Fang Gong, Xiao-Li Zhang, Wen-Guang Tian, Li Hu, Xian-Xiang Zhang, Jiang-Lin Xiang, Hong-Xin Du, Hua-Wen Liu, Chun-Hui Lang, Xiao-He Luo, Shao-Bo Wu, Xiao-Ping Cui, Zheng Zhou, Man-Man Zhu, Jing Wang, ChengJun Xue, Xiao-Feng Li, Li Wang, Zhi-Jie Li, Kun Wang, Chang-Chun Niu, Qing-Jun Yang, Xiao-Jun Tang, Yong Zhang, Xia-Mao Liu, Jin-Jing Li, De-Chun Zhang, Fan Zhang, Ping Liu, Jun Yuan, Qin Li, Jie-Li Hu, Juan Chen, and Ai-Long Huang. Antibody responses to SARS-CoV-2 in patients with COVID-19. Nature Medicine, 26(6):845-848, jun 2020.

37. Anna Bläckberg, Nils Fernström, Emma Sarbrant, Magnus Rasmussen, and Torgny Sunnerhagen. Antibody kinetics and clinical course of COVID-19 a prospective observational study. Plos One, 16(3):e0248918, mar 2021.

38. RECOVERY Collaborative Group. Convalescent plasma in patients admitted to hospital with COVID-19 (RECOVERY): a randomised controlled, open-label, platform trial. The Lancet, 397(10289):2049-2059, may 2021.

39. Patti A Longo, Jennifer M Kavran, Min-Sung Kim, and Daniel J Leahy. Transient mammalian cell transfection with polyethylenimine (PEI). Methods in Enzymology, 529:227-240, 2013.

40. Charlotta Preger, Edvard Wigren, Elena Ossipova, Carolyn Marks, Johan Lengqvist Camilla Hofström, Oskar Andersson, Per-Johan Jakobsson, Susanne Gräslund, and Helena Persson. Generation and validation of recombinant antibodies to study human aminoacyltRNA synthetases. The Journal of Biological Chemistry, 295(41):13981-13993, oct 2020.

41. Anna Säll, Maria Walle, Christer Wingren, Susanne Müller, Tomas Nyman, Andrea Vala, Mats Ohlin, Carl A K Borrebaeck, and Helena Persson. Generation and analyses of human synthetic antibody libraries and their application for protein microarrays. Protein Engineering, Design \& Selection, 29(10):427-437, oct 2016.

42. Wael Bahnan, Lotta Happonen, Hamed Khakzad, Vibha Kumra Ahnlide, Therese de Neergaard, Sebastian Wrighton, Eleni Bratanis, Di Tang, Thomas Hellmark, Lars Bjorck, Oonagh Shannon, Lars Malmstrom, Johan Malmstrom, and Pontus Nordenfelt. Protection induced by a human monoclonal antibody recognizing two different epitopes in a conserved region of streptococcal $\mathrm{m}$ proteins. BioRxiv, mar 2021. 